\title{
Shear enhancement near supports in RC beams
}

Robert L. Vollum

Reader in Concrete Structures, Department of Civil and Environmental Engineering, Imperial College London, London, UK

\section{Libin Fang}

Former PhD student, Department of Civil and Environmental Engineering, Imperial College London, London, UK

Shear strength is enhanced within the short shear span of reinforced concrete beams that are loaded on their upper side within a distance of around $2-2 \cdot 5 d$ of supports (where $d$ is the beam effective depth). Eurocode 2 and fib Model Code 2010 (MC2010) account for this by reducing the design shear force, unlike the previous UK code BS 8110, which increases the shear resistance provided by concrete. Eurocode 2 and MC2010 also allow shear enhancement to be modelled using strut-and-tie models. Very few test data are available to assess the comparative merits of these approaches for the design of beams with multiple point loads within $2 d$ of supports. Consequently, 12 beams were tested to investigate the influence of loading arrangement on shear resistance. Comparisons are made between the strengths of the tested beams and the predictions of BS 8110, Eurocode 2, MC2010, strut-and-tie modelling and nonlinear finite-element analysis. Significantly, the BS 8110 approach of enhancing shear resistance is found to give better strength predictions than the load reduction methods of Eurocode 2 and MC2010. Accuracy of the non-linear finiteelement analysis and strut-and-tie model is broadly comparable, but the former requires calibration, unlike the latter.

\section{Notation}

$A_{\mathrm{s}} \quad$ cross-sectional area of flexural tension reinforcement

$A_{\mathrm{sl}} \quad$ area of flexural tension reinforcement

$A_{\text {sw }} \quad$ cross-sectional area of each set of stirrups

$a_{\mathrm{v}} \quad$ clear shear span between adjacent edges of load and support

$b_{\mathrm{w}} \quad$ effective web width, which equals $b$ for rectangular section

$c$ distance from bottom of beam to centroid of bottom flexural reinforcement

$d$ beam effective depth

$d_{\mathrm{g}} \quad$ maximum aggregate size

$E_{\mathrm{s}} \quad$ elastic modulus of reinforcement

$e_{i} \quad$ distance to line of action of stirrup force $T_{\mathrm{si}}$ from centreline of support

$f_{\mathrm{c}} \quad$ measured concrete cylinder strength

$f_{\text {cd }}$ design concrete uniaxial compressive strength

$f_{\mathrm{ck}} \quad$ characteristic concrete cylinder strength

$f_{\text {cnt }} \quad$ flexural compressive stress used in strut-and-tie model

$f_{\text {csb }} \quad$ concrete strength at bottom end of direct strut

$f_{\text {cst }} \quad$ concrete strength at top end of direct strut

$f_{\mathrm{y}} \quad$ yield strength of reinforcement

$f_{\text {yd }} \quad$ design yield strength of reinforcement

$h$ beam depth

$k_{\mathrm{c}} \quad$ coefficient used by MC2010 in calculation of maximum possible shear resistance

$k_{\mathrm{V}} \quad$ coefficient used my MC2010 in calculation shear resistance provided by concrete

$k_{\varepsilon} \quad$ coefficient used in calculation of maximum shear resistance $l_{\mathrm{b}} \quad$ length of support

$l_{\mathrm{t}} \quad$ length of loaded area

$M_{\mathrm{fd}} \quad$ moment at the control section for shear

$n_{\text {ave }} \quad$ number of stirrups with cross-sectional area $A_{\mathrm{sw}}$ within central three-quarters of clear shear span $a_{\mathrm{vs}}$

$s \quad$ stirrup spacing

$T_{\mathrm{d}} \quad$ longitudinal component of force resisted by strut III

$T_{i}^{\prime} \quad$ longitudinal component of force resisted by strut VII

$T_{\mathrm{si}} \quad$ yield capacity of stirrups in tie $T_{\mathrm{si}}$

$V_{\mathrm{Rd}}$ design shear resistance

$V_{\text {Rdc }}$ design shear resistance provided by the concrete alone

$V_{\text {calc }}$ calculated shear resistance

$V_{\text {test }}$ measured shear resistance

$w_{\mathrm{b}} \quad$ width of strut III at its bottom end

$w_{\mathrm{t}} \quad$ width of strut III at its top end

$\alpha \quad$ inclination of strut VII to the horizontal

$\beta \quad$ proportion of force $T_{\mathrm{d}}+T_{i}^{\prime}$ transferred to bottom node by strut III

$\gamma_{\mathrm{c}} \quad$ partial factor for concrete

$\gamma_{\mathrm{s}} \quad$ material factor of safety for reinforcement

$\varepsilon_{x} \quad$ longitudinal strain at mid-depth of member

$\eta_{\mathrm{fc}} \quad$ coefficient used in calculation of maximum shear resistance

$\theta \quad$ inclination of strut III to the horizontal

$\kappa \quad P_{2} / P_{1}$, where $P_{1}$ and $P_{2}$ are defined in Figure 3

$\lambda \quad$ proportion of shear force carried by strut III

\section{Introduction}

The present research was prompted by differences between the approaches adopted in BS 8110 (BSI, 1997), Eurocode 2 (BSI, 
2004) and fib Model Code 2010 (MC2010) (fib, 2013) for modelling shear enhancement, which is assumed to occur when beams are loaded on their upper side within $2 d$ of supports. BS 8110 increases the shear resistance provided by concrete by the multiple $2 d / a_{\mathrm{v}}$ (where $a_{\mathrm{v}}$ is the clear shear span), unlike Eurocode 2 and MC2010 which reduce the component of the design shear force due to loads applied on the upper side of the beam within $2 d$ of supports by the multiple $a_{\mathrm{v}} / 2 d$. All three codes also limit the maximum possible shear resistance. MC2010 and Eurocode 2 also allow the strut-and-tie method (STM) to be used to model shear enhancement near supports, bringing into question which method to use. Many beams have been tested with single concentrated loads within $2 d$ of supports, but there is an almost complete lack of data on beams with two or more concentrated loads within $2 d$ of supports (Brown and Bayrak, 2007). To address this omission, the authors tested 12 simply supported beams with up to two point loads positioned within $2 d$ of each support. The tests investigated the influences on shear resistance of reinforcement, concrete cover, bearing plate dimensions and loading arrangement. This paper briefly describes the beam tests and a STM that is suitable for the analysis of beams with up to two point loads adjacent to supports. Full details of the beam tests and STM can be found elsewhere (Fang, 2014; Vollum and Fang, 2014). The main contribution of this paper is the comparative evaluation of STM, non-linear finite-element analysis (NLFEA) and the sectional shear enhancement methods of BS 8110, Eurocode 2 and MC2010. This is done through parametric studies and analysis of data from the tested beams and 57 other short-span beams with shear reinforcement. The parametric studies investigate the influence of loading arrangements not considered in the tests. NLFEA is used to assess the influence of varying the loading arrangement on the shear strength of beams with the same geometry and reinforcement arrangements as those tested by the authors. The predictions of the STM and codified sectional design methods are subsequently compared with the NLFEA predictions. Suggestions are also made for improving the shear enhancement provisions of Eurocode 2.

\section{Description of beam tests}

The beams were cast in two groups of six, which are denoted series 1 and 2. The beam geometry and reinforcement arrangements are shown in Figures 1 and 2 for series 1 and 2, respectively. The first six beams were $500 \mathrm{~mm}$ deep $\times 160 \mathrm{~mm}$ wide and were reinforced with two $25 \mathrm{~mm}$ diameter high-tensile reinforcement bars as shown in Figure 1. The cover to the flexural reinforcement was either $25 \mathrm{~mm}$ or $50 \mathrm{~mm}$. The cover was varied because STM predicts the strength to increase with cover, whereas the sectional design methods of BS 8110, Eurocode 2 and MC2010 predict the strength to decrease owing to the reduction in effective depth $d$. The second six beams, which measured $505 \mathrm{~mm}$ deep $\times 165 \mathrm{~mm}$ wide, were grouped into three pairs which are depicted A, S1 and S2, of which pair A was unreinforced in shear. Unlike the first set, four $8 \mathrm{~mm}$ diameter stirrups were provided at the ends of the beams to improve the anchorage of the flexural reinforcement. Two arrangements of

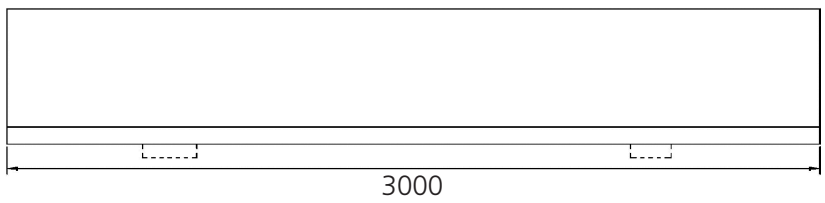

(a)

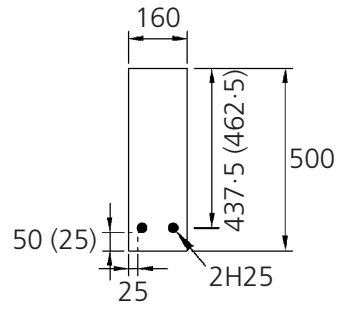

(b)

Figure 1. Reinforcement arrangement for series 1 beams:

(a) elevation; (b) cross-section

shear reinforcement were used, $\mathrm{S} 1$ and $\mathrm{S} 2$, which are depicted in Figures 2(b) and 2(c), respectively. Figure 3, which should be read in conjunction with Table 1, gives details of the loading arrangements. In all the tests, loads were applied with a single actuator that reacted against an internal reaction frame. All the loading and support plates were $50 \mathrm{~mm}$ thick. Figure 3(d) shows the method of load application for loading arrangement $\mathrm{C}$ with four point loads. The shaded rollers in Figure 3(d) were fixed by welding the roller to the lower bearing plate. The test specimen was supported on bearings which allowed horizontal translation as well as rotation. In loading arrangement B with two point loads, the solid steel beams shown in Figure 3(d) were omitted and the test specimen was loaded through the concrete-filled rectangular hollow section (RHS). No instabilities were encountered for any of the loading arrangements as failure was approached. Furthermore, the reactions measured at the right-hand end of the beam showed that the loads were applied as intended. The stirrup positions in Figure 2(c) were chosen to clarify the definition of the ties $T_{\mathrm{s} 1}$ and $T_{\mathrm{s} 2}$ in the STM of Figure 4. In each set of beams, failure was expected to occur on the side of the narrowest support, which was on the right-hand side as seen in Figure 3.

The beams were cast from ready-mix concrete in which the coarse aggregate was marine dredged gravel with a maximum aggregate size of $10 \mathrm{~mm}$. Push-off tests were not carried out as the aggregate was similar to that tested by Sagaseta and Vollum (2011a, 2011b). Twelve concrete cylinders were cast with each batch of beams, of which six were cured in air alongside the beams and six in water at $20^{\circ} \mathrm{C}$. Three water- and three air-cured cylinders were tested at the same time as the first and last beams of each series. Table 2 shows the estimated water-cured concrete strengths at the times of testing the beams, which were derived assuming a linear increase in strength between the times of testing of the first and last beams in each group. The strength of the air-cured cylinders was on average around $5 \%$ less than that of the water-cured cylinders, which were used in the strength assessments of the beams to give 


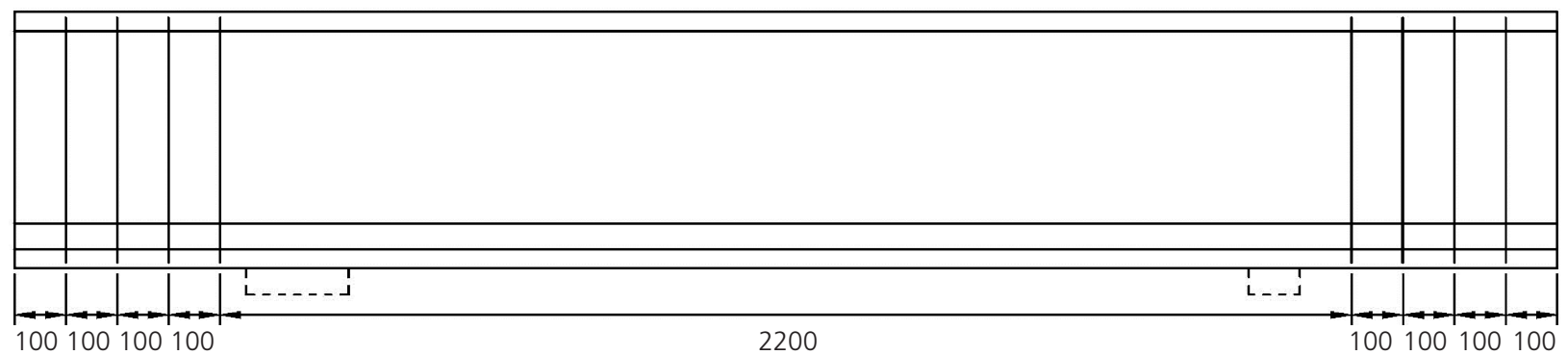

(a)

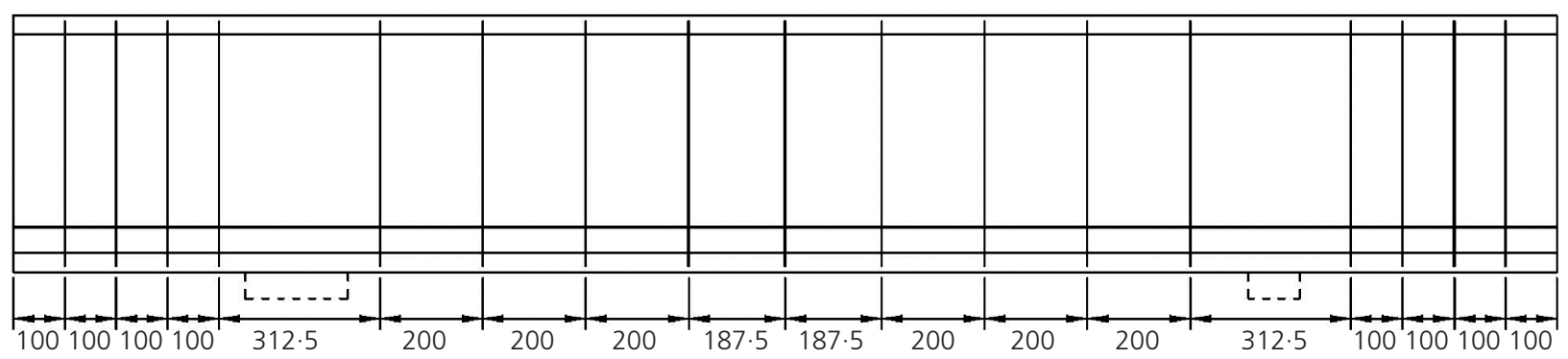

(b)

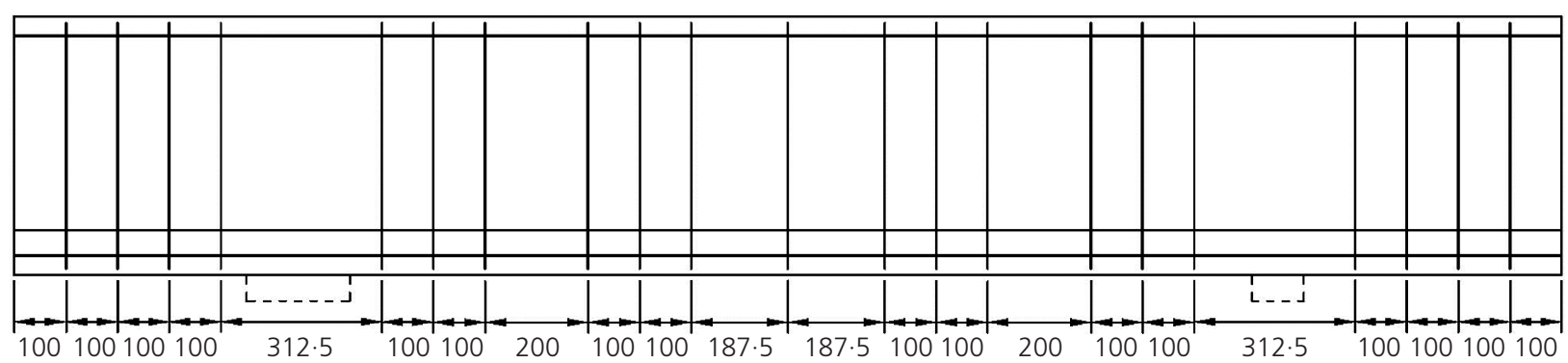

(c)

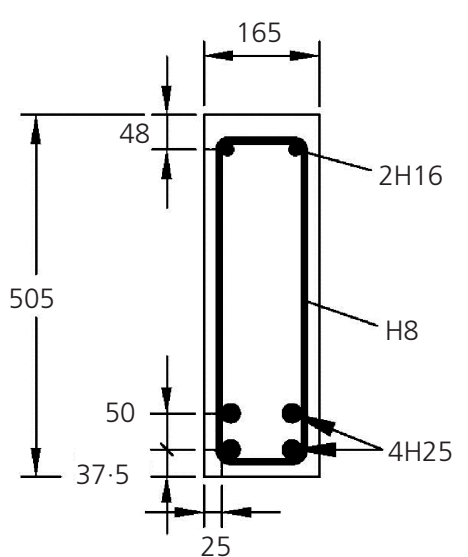

(d)

Figure 2. Reinforcement arrangement for series 2 beams: (a) A beams; (b) S1 beams; (c) S2 beams; (d) cross-section

an upper bound to the predicted strengths. Table 3 gives the reinforcement $0 \cdot 2 \%$ offset yield strengths.

Reinforcement strains were estimated in all of the beams from displacements measured between Demec points mounted on the concrete surface along the reinforcement. Strains were also measured with electrical resistance strain gauges in the flexural and shear reinforcement of beams A-1, S1-1 and S2-1. The gauges were positioned in the shear span adjacent to the narrowest support, which STM predicts to be critical. In reality, beams S1-1 


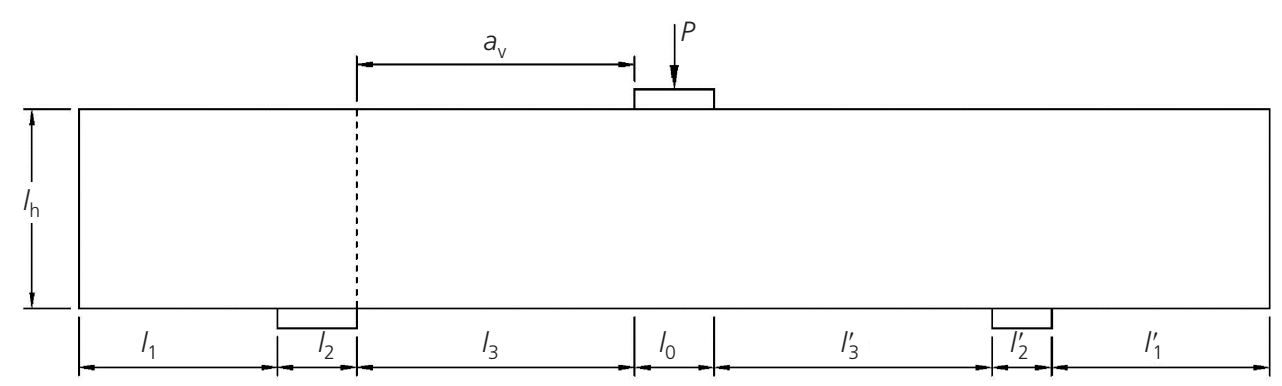

(a)

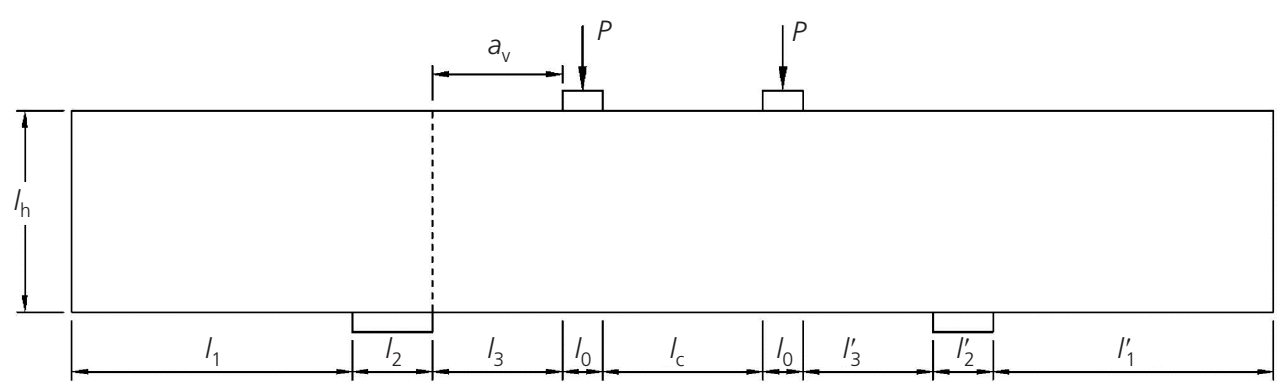

(b)

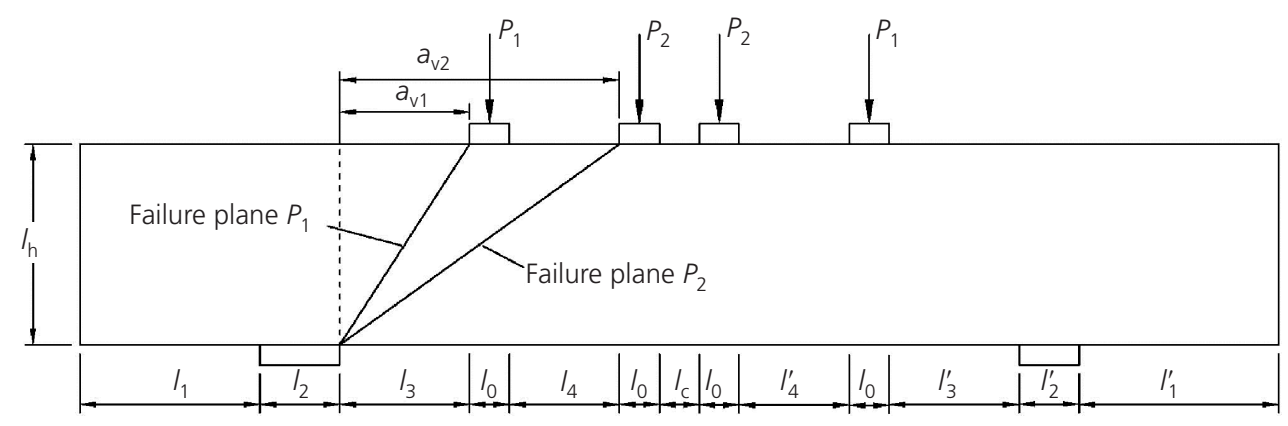

(c)

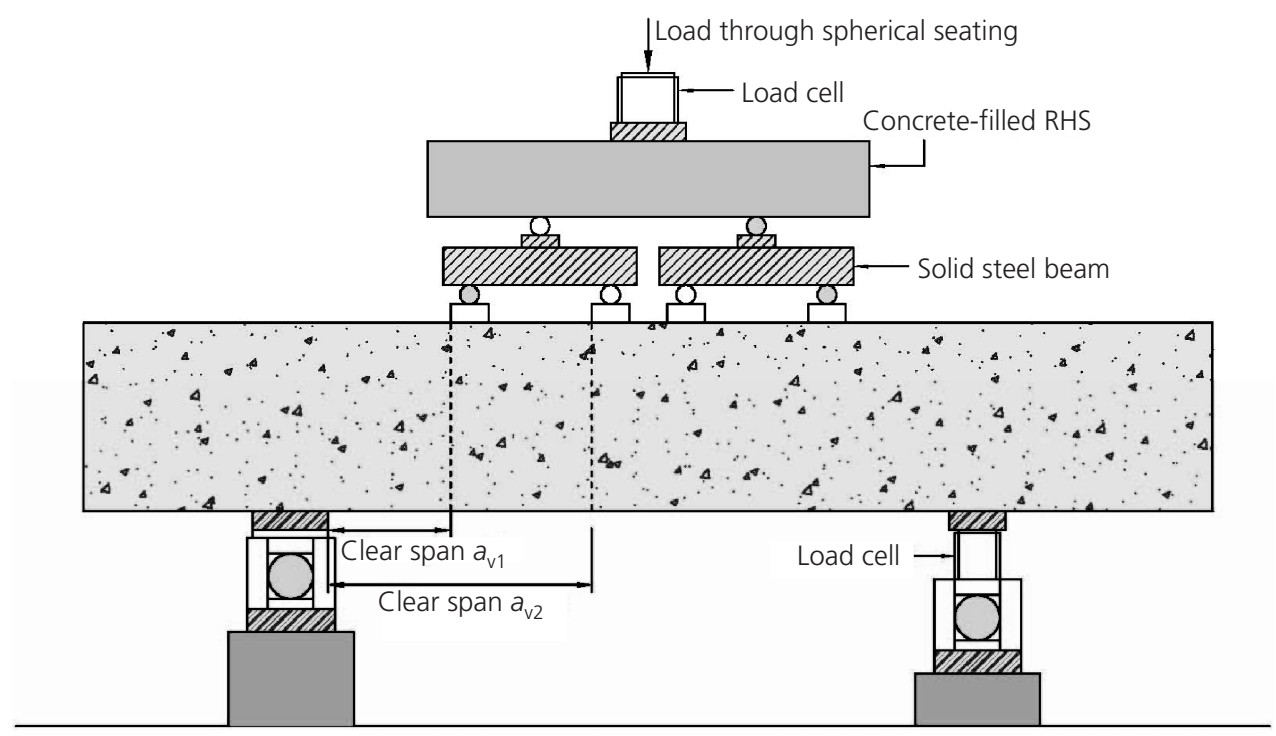

(d)

Figure 3. Loading arrangements: (a) $A$; (b) $B$; (c) C; (d) loading rig for $\mathrm{C}$ 


\begin{tabular}{|c|c|c|c|c|c|c|c|c|c|c|c|c|c|}
\hline Beams & $\begin{array}{l}\text { Load } \\
\text { arrangement }\end{array}$ & $\begin{array}{c}\text { Rebar } \\
\text { arrangement }\end{array}$ & 10 & $I_{1}$ & $l_{1}^{\prime}$ & $1 / 2$ & $I_{2}^{\prime}$ & 13 & $I_{3}^{\prime}$ & $I_{4}$ & $I_{4}^{\prime}$ & $I_{c}$ & $\operatorname{lh}$ \\
\hline B1-25 & A & $1 a$ & 200 & 500 & 550 & 200 & 150 & 700 & 700 & - & - & - & 500 \\
\hline $\mathrm{B} 1-50^{\mathrm{a}}$ & A & $1 a$ & 200 & 500 & 550 & 200 & 150 & 700 & 700 & - & - & - & 500 \\
\hline$B 2-25^{a}$ & B & $1 a$ & 100 & 700 & 700 & 200 & 150 & 325 & 325 & - & - & 400 & 500 \\
\hline$B 2-50^{a}$ & B & $1 a$ & 100 & 700 & 700 & 200 & 150 & 325 & 325 & - & - & 400 & 500 \\
\hline B3-25 & C & $1 a$ & 100 & 450 & 500 & 200 & 150 & 325 & 325 & 275 & 275 & 100 & 500 \\
\hline B3-50 & C & $1 a$ & 100 & 450 & 500 & 200 & 150 & 325 & 325 & 275 & 275 & 100 & 500 \\
\hline$A-2^{b}$ & B & $2 a$ & 100 & 450 & 500 & 200 & 100 & 700 & 750 & - & - & 100 & 505 \\
\hline$S 1-2^{b}$ & B & $2 b$ & 100 & 450 & 500 & 200 & 100 & 700 & 750 & - & - & 100 & 505 \\
\hline$S 2-2^{b}$ & B & $2 c$ & 100 & 450 & 500 & 200 & 100 & 700 & 750 & - & - & 100 & 505 \\
\hline$A-1^{b}$ & C & $2 a$ & 100 & 450 & 500 & 200 & 100 & 325 & 375 & 275 & 275 & 100 & 505 \\
\hline$S 1-1^{b}$ & C & $2 b$ & 100 & 450 & 500 & 200 & 100 & 325 & 375 & 275 & 275 & 100 & 505 \\
\hline$S 2-1^{b}$ & C & $2 c$ & 100 & 450 & 500 & 200 & 100 & 325 & 375 & 275 & 275 & 100 & 505 \\
\hline
\end{tabular}

a Series 1.

${ }^{\mathrm{b}}$ Series 2.

c Figure number in which reinforcement is shown.

Table 1. Description of loading arrangements (to be read in conjunction with Figure 3)

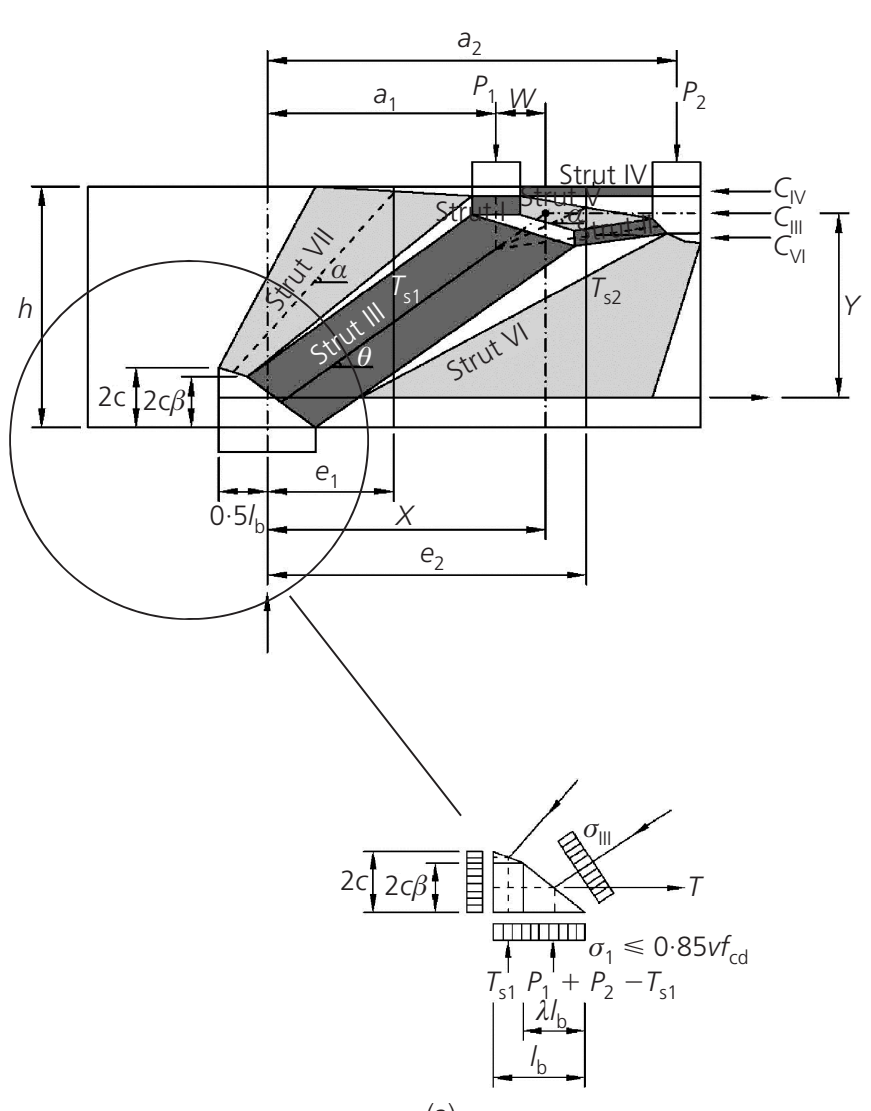

(a)

Figure 4. STM for beams with two point loads within $2 d$ of a support: (a) STMa for $P_{2} \geqslant T_{s 1}+T_{s 2}$; (b) STMb for $P_{2}<T_{s 1}+T_{s 2}$; (c) STMc with no shear reinforcement (adapted from Vollum and Fang, 2014)
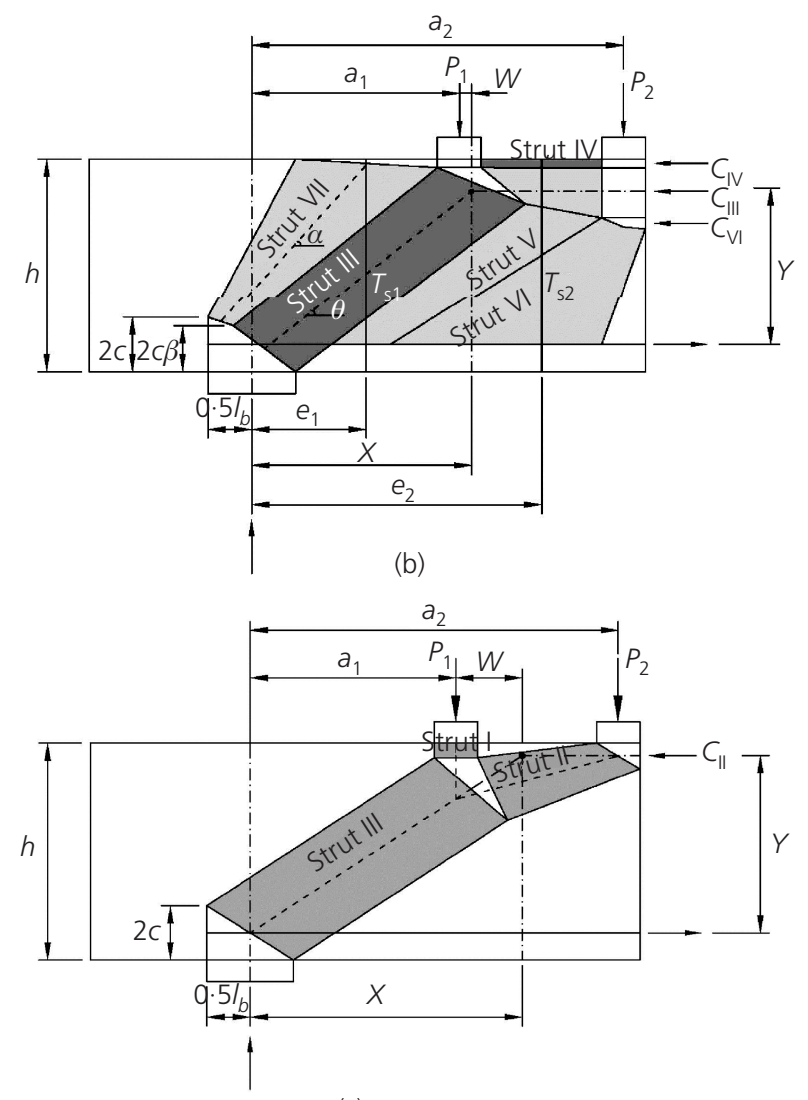

(c) 


\begin{tabular}{|c|c|c|c|c|c|c|c|c|c|c|c|}
\hline \multirow[t]{3}{*}{ Beam } & \multirow[t]{3}{*}{$f_{\mathrm{c}}: \mathrm{MPa}$} & \multirow[t]{3}{*}{ No. loads } & \multirow[t]{3}{*}{$d: m m$} & \multicolumn{2}{|c|}{$\Sigma P: k N$} & \multicolumn{6}{|c|}{$P_{\text {test }} / P_{\text {calc }}$} \\
\hline & & & & \multirow[t]{2}{*}{ Test } & \multirow[t]{2}{*}{ Flex ${ }^{a}$} & \multicolumn{2}{|c|}{$\begin{array}{l}\text { Eurocode } 2 \\
\text { Equation } 4\end{array}$} & \multicolumn{2}{|c|}{ BS 8110} & \multicolumn{2}{|c|}{ MC2010 } \\
\hline & & & & & & $L^{b}$ & $R^{b}$ & $L^{b}$ & $R^{b}$ & $L^{b}$ & $R^{b}$ \\
\hline B1-25 & $45 \cdot 7$ & 1 & $462 \cdot 5$ & 368 & 558 & $1 \cdot 61$ & $1 \cdot 61$ & $1 \cdot 61$ & $1 \cdot 61$ & $1 \cdot 75$ & 1.73 \\
\hline B1-50 & $45 \cdot 7$ & 1 & $437 \cdot 5$ & 352 & 510 & 1.67 & $1 \cdot 67$ & $1 \cdot 67$ & $1 \cdot 67$ & $1 \cdot 78$ & $1 \cdot 77$ \\
\hline B2-25 & $45 \cdot 7$ & 2 & $462 \cdot 5$ & 977 & 1001 & 1.98 & 1.98 & 1.98 & 1.98 & $3 \cdot 54$ & $3 \cdot 50$ \\
\hline B2-50 & $45 \cdot 7$ & 2 & $437 \cdot 5$ & 929 & 942 & $2 \cdot 04$ & $2 \cdot 04$ & $2 \cdot 04$ & $2 \cdot 04$ & $3 \cdot 45$ & $3 \cdot 42$ \\
\hline$A-2$ & $34 \cdot 6$ & 2 & $442 \cdot 5$ & 349 & 890 & $1 \cdot 53$ & $1 \cdot 64$ & $1 \cdot 53$ & $1 \cdot 64$ & $1 \cdot 54$ & $1 \cdot 61$ \\
\hline S1-2 & $36 \cdot 0$ & 2 & $442 \cdot 5$ & 601 & 890 & 1.09 & $1 \cdot 17$ & $1 \cdot 19$ & $1 \cdot 27$ & $1 \cdot 04$ & 1.08 \\
\hline S2-2 & $36 \cdot 7$ & 2 & $442 \cdot 5$ & 820 & 890 & 1.00 & 1.07 & $1 \cdot 27$ & $1 \cdot 36$ & $1 \cdot 05$ & $1.08^{d}$ \\
\hline B3-25 & $45 \cdot 7$ & 4 & $462 \cdot 5$ & 480 & 726 & $1 \cdot 53$ & $1 \cdot 53$ & 1.05 & 1.05 & $2 \cdot 02$ & $2 \cdot 00$ \\
\hline B3-50 & $45 \cdot 7$ & 4 & $437 \cdot 5$ & 580 & 684 & $2 \cdot 01$ & $2 \cdot 01$ & $1 \cdot 37$ & $1 \cdot 37$ & $2 \cdot 56$ & $2 \cdot 53$ \\
\hline$A-1$ & $33 \cdot 1$ & 4 & $442 \cdot 5$ & 823 & 1235 & $2 \cdot 68$ & 2.94 & $1 \cdot 83$ & 1.96 & $3 \cdot 19$ & $3 \cdot 24$ \\
\hline S1-1 & $33 \cdot 7$ & 4 & $442 \cdot 5$ & 1000 & 1235 & $1 \cdot 76$ & 1.95 & $1 \cdot 28$ & $1 \cdot 47$ & $1 \cdot 53$ & $1 \cdot 55$ \\
\hline S2-1 & $35 \cdot 2$ & 4 & $442 \cdot 5$ & 1179 & 1235 & $1 \cdot 38$ & $1 \cdot 53$ & $1 \cdot 26$ & 1.45 & $1 \cdot 33$ & $1 \cdot 34^{d}$ \\
\hline
\end{tabular}

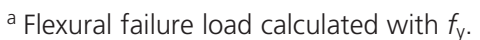

${ }^{b}$ Calculated for right (R)/left (L) shear span as defined in Figure 3 (bold type denotes critical shear span in test).

' Level 2 for beams without shear reinforcement and level 3 for beams with shear reinforcement.

${ }^{d}$ Calculated with average stirrup spacing of $120 \mathrm{~mm}$.

Table 2. Measured and predicted failure loads

\begin{tabular}{lcc}
\hline Type & $E_{\mathrm{s}}: \mathrm{GPa}$ & $f_{\mathrm{y}}: \mathrm{MPa}$ \\
\hline $\mathrm{H} 8$ & 200 & 540 \\
$\mathrm{H} 16$ & 200 & 540 \\
$\mathrm{H} 25$ & 200 & 560
\end{tabular}

Eurocode 2:

1a. $\beta_{1} P_{1}+\beta_{2} P_{2} \leqslant V_{\mathrm{Rdav} 1}=\max \left(V_{\mathrm{Rd}, \mathrm{c}}, n_{\mathrm{av} 1} A_{\mathrm{sw}} f_{\mathrm{yd}}\right)$

Table 3. Reinforcement properties

and S2-2 unexpectedly failed on the side of the wider support, which has implications for design when using STM. The failure loads of all the beams are listed in Table 2, which also gives the calculated flexural failure loads and the shear span within which failure occurred.

\section{Shear enhancement in Eurocode 2, MC2010 and BS 8110}

MC2010 and Eurocode 2 reduce the component of the design shear force due to loads applied within $2 d$, unlike BS 8110 which increases the shear resistance provided by concrete. However, MC2010 and BS 8110 add the design shear resistances provided by the concrete and shear reinforcement, unlike Eurocode 2 which takes the shear resistance as the greater of the two. BS 8110 and Eurocode 2 assume stirrups to be effective if positioned within the central three-quarters of the clear shear span. The three design methods are compared below for beams symmetrically loaded with two point loads positioned within $2 d$ of each support, as shown in Figure 3(c).
MC2010:

2. $\beta_{1} P_{1}+\beta_{2} P_{2} \leqslant V_{\mathrm{Rd}}$

3. $\beta_{1}=\frac{a_{\mathrm{v} 1}}{2 d}, \beta_{2}=\frac{a_{\mathrm{v} 2}}{2 d}$

where $V_{\mathrm{Rd}}$ is the design shear resistance, $V_{\mathrm{Rd}, \mathrm{c}}$ is the design shear resistance provided by the concrete alone and $n_{\mathrm{av} i}$ is the number of stirrups with cross-sectional area $A_{\text {sw }}$ within the central threequarters of the clear shear span $a_{v i}$, which is defined in Figure 3(c). Eurocode 2 limits $\beta$ to a minimum of $0 \cdot 25$, whereas MC2010 limits it to a minimum of $0 \cdot 5$.

Equation 1 gives rise to illogical results for load case $\mathrm{C}$ of Figure 3(c) if $n_{\mathrm{av} 1} A_{\mathrm{sw}} f_{\mathrm{yd}}>V_{\mathrm{Rd}, \mathrm{c}}$, since the application of an infinitesimally small load at $a_{\mathrm{v} 1}$ reduces the design shear resistance from 
$n_{\mathrm{av} 2} A_{\mathrm{sw}} f_{\mathrm{yd}}$ to $n_{\mathrm{av} 1} A_{\mathrm{sw}} f_{\mathrm{yd}}$. Other ambiguities in Equation 1 have been reported by Jackson et al. (2007). The illogicality of Equation 1 arises when $V_{\text {Rdav1 }}<V_{\text {Rdav2 }}$ and can be avoided by interpreting Eurocode 2 as follows

\section{4. $\beta_{1} P_{1} / V_{\mathrm{Rdav} 1}+\beta_{2} P_{2} / V_{\mathrm{Rdav} 2} \leqslant 1$}

in which $V_{\mathrm{Rdav} 1}$ and $V_{\mathrm{Rdav} 2}$ are defined in Equation 1.

According to BS 8110 , failure occurs along either plane $P_{1}$ or $P_{2}$ in Figure 3(c) for which

5a. $\quad \beta_{1}\left(P_{1}+P_{2}\right) \leqslant V_{\mathrm{Rdav} 1}=\left(V_{\mathrm{Rd}, \mathrm{c}}+0 \cdot 5 n_{\mathrm{av} 1} A_{\mathrm{sw}} f_{\mathrm{yd}}\right)$

5b. $\quad \beta_{2} P_{2} \leqslant V_{\mathrm{Rdav} 2}=\left(V_{\mathrm{Rd}, \mathrm{c}}+0 \cdot 5 n_{\mathrm{av} 2} A_{\mathrm{sw}} f_{\mathrm{yd}}\right)$

BS 8110 takes the failure load as the least of the enhanced shear resistances $V_{\text {Rdav1 }} / \beta_{1}$ and $V_{\text {Rdav2 }} / \beta_{2}$, which avoids the illogicality that arises with Equation 1. Consideration of Equations 5(a) and 5 (b) shows that for uniformly distributed stirrups at spacing $s$, the enhanced shear reinforcement contribution is $V_{\mathrm{Rd}, \mathrm{s}}=$ $0.75\left(A_{\mathrm{sw}} / s\right) d f_{\mathrm{ywd}}$ if $n_{\mathrm{av}}=0.75 a_{\mathrm{v}} / s$. The corresponding enhanced shear reinforcement contribution from Equation 1(b) is $V_{\mathrm{Rd}, \mathrm{s}}=1 \cdot 5\left(A_{\mathrm{sw}} / s\right) d f_{\mathrm{ywd}}$, which implies Eurocode 2 gives no shear enhancement when the shear resistance is governed by shear reinforcement. Equation 2 of MC2010 avoids the problems of Equation 1 by making the shear resistance $V_{\mathrm{Rd}}$ independent of $a_{\mathrm{v}}$.

\section{Calculation of shear resistance with Eurocode 2 and MC2010}

Eurocode 2 and MC2010 use the following equations to calculate the design shear resistance $V_{\mathrm{Rd}}$ of reinforced concrete beams with $a_{\mathrm{v}} / d>2$.

Eurocode 2: $V_{\mathrm{Rd}}=\max \left(V_{\mathrm{Rd}, \mathrm{c}}, V_{\mathrm{Rd}, \mathrm{s}}\right)$ where

$$
\begin{aligned}
& V_{\mathrm{Rd}, \mathrm{c}}(\text { Eurocode } 2)=0 \cdot 18 b_{\mathrm{w}} d \\
& \times\left(\frac{100 A_{\mathrm{sl}}}{b d} f_{\mathrm{ck}}\right)^{1 / 3}\left(1+\sqrt{\frac{200}{d}}\right) / \gamma_{\mathrm{c}}
\end{aligned}
$$

7. $V_{\mathrm{Rd}, \mathrm{s}}=0.9 A_{\mathrm{sw}} f_{\mathrm{yd}} d \cot \theta / s \leqslant V_{\mathrm{Rd}, \text { max }}$ where $A_{\mathrm{sl}}$ is the area of flexural tension reinforcement, $b_{\mathrm{w}}$ is the width of the cross-section, $d$ is the beam effective depth, $V_{\mathrm{Rd}, \mathrm{s}}$ is the design shear resistance with shear reinforcement, $z=0.9 d$ and $f_{\mathrm{ck}}$ is the characteristic compressive concrete cylinder strength. $v_{1}=0 \cdot 6\left[1-\left(f_{\text {ck }} / 250\right)\right] f_{\text {cd }}$ and $1 \leqslant \cot \theta \leqslant 2 \cdot 5$. The reinforcement ratio $A_{\mathrm{sl}} / b d$ is limited to a maximum of 0.02 in Equation 6. $\gamma_{\mathrm{c}}$ is a partial factor for concrete which has a design value of 1.5 but is taken as 1.0 in the strength assessments of this paper. Eurocode 2 does not define the value of $\cot \theta$ to be used in Equation 8 when $a_{\mathrm{v}}<2 d$. This omission is rectified in the background document to the UK National Annex to Eurocode 2 (BSI, 2010), which takes $\cot \theta$ at $a_{\mathrm{v}} / h$ but not less than $1 \cdot 0$.

MC2010 gives four levels of design approximation for shear, of which levels 2 and 3 are intended for detailed design and assessment of existing structures.

MC2010 level 2: $V_{\mathrm{Rd}}=\max \left(V_{\mathrm{Rd}, \mathrm{c}}, V_{\mathrm{Rd}, \mathrm{s}}\right)$ where

9 .

$$
V_{\mathrm{Rd}, \mathrm{c}}(\mathrm{MC} 2010)=k_{\mathrm{v}} \frac{\sqrt{f_{\mathrm{ck}}}}{\gamma_{\mathrm{c}}} z b_{\mathrm{w}}
$$

10. $k_{\mathrm{v}}=\frac{0 \cdot 4}{1+1500 \varepsilon_{x}} \frac{1300}{1000+k_{\mathrm{dg}} z}$

11. $k_{\mathrm{dg}}=\frac{32}{16+d_{\mathrm{g}}} \geqslant 0 \cdot 75$

12.

$$
\varepsilon_{x}=\frac{1}{2 E_{\mathrm{s}} A_{\mathrm{s}}}\left(\frac{M_{\mathrm{Ed}}}{z}+V_{\mathrm{Ed}}\right) \geqslant \frac{V_{\mathrm{Ed}}}{2 E_{\mathrm{s}} A_{\mathrm{s}}}\left[\frac{\left(d+0 \cdot 5 l_{\mathrm{b}}\right)}{z}+1\right]
$$

where $d_{\mathrm{g}}$ is the maximum aggregate size, $l_{\mathrm{b}}$ is the length of the support, $z=0.9 d$ and $M_{\mathrm{Ed}}$ is the moment at the control section for shear, which is located at a distance $d$ from the edge of supports or concentrated loads. The former control section governs for the beams considered in this paper as $a_{\mathrm{v}} \leqslant 2 d$.

13. $V_{\mathrm{Rd}, \mathrm{s}}=\frac{A_{\mathrm{sw}}}{s} z f_{\mathrm{yd}} \cot \theta \leqslant V_{\mathrm{Rd}, \text { max }}$

14. $V_{\mathrm{Rdmax}}=k_{\mathrm{c}} \frac{f_{\mathrm{ck}}}{\gamma_{\mathrm{c}}} b_{\mathrm{w}} z \sin \theta \cos \theta$

15. $\theta_{\min }=20^{\circ}+1000 \varepsilon_{x}$

8. $V_{\mathrm{Rd}, \text { max }}=0 \cdot 9 b_{\mathrm{w}} d v_{1} f_{\mathrm{cd}} /(\cot \theta+\tan \theta)$ 


$$
k_{\mathrm{c}}=k_{\varepsilon} \eta_{\mathrm{fc}}=\frac{1}{1 \cdot 2+55 \varepsilon_{1}}\left(\frac{30}{f_{\mathrm{ck}}}\right)^{1 / 3}
$$

16. where $\frac{1}{1 \cdot 2+55 \varepsilon_{1}} \leqslant 0.65$ and $\left(\frac{30}{f_{\text {ck }}}\right)^{1 / 3} \leqslant 1$

17. $\varepsilon_{1}=\varepsilon_{x}+\left(\varepsilon_{x}+0 \cdot 002\right) \cot ^{2} \theta$

MC2010 level 3: $V_{\mathrm{Rd}}=V_{\mathrm{Rd}, \mathrm{c}}+V_{\mathrm{Rd}, \mathrm{s}}$ where all the terms are as defined above except

18.

$$
k_{\mathrm{v}}=\frac{0 \cdot 4}{1+1500 \varepsilon_{x}}\left[1-\frac{V_{\mathrm{Ed}}}{V_{\mathrm{Rd}, \max }\left(\theta_{\min }\right)}\right] \geqslant 0
$$

\section{Evaluation of shear enhancement methods of MC2010, BS 8110 and Eurocode 2}

The shear enhancement methods of MC2010, BS 8110 and Eurocode 2 were used, with $\gamma_{\mathrm{c}}=\gamma_{\mathrm{s}}=1 \cdot 0$, to predict the strengths of the authors' beams. The Eurocode 2 strengths were calculated with Equation 4 as Equation 1 incorrectly predicts the strengths of beams with shear reinforcement to be less under loading arrangement $\mathrm{C}$ with four point loads than loading arrangement $\mathrm{B}$ with two. Equation 4 avoids this illogicality, but incorrectly gives the same shear enhancement for load cases B and C as $\beta_{1} / n_{\mathrm{av} 1}=\beta_{2} / n_{\mathrm{av} 2}$, whereas in reality the enhancement was greater for the tested beams under loading combination $C$ than B. In order to compare the respective merits of the shear enhancement methods in BS 8110 and Eurocode 2, the BS 8110 strengths were calculated using Equation 5 with $V_{\mathrm{Rd}, \mathrm{c}}$ from Equation 6 of Eurocode 2. The maximum possible shear resistance $V_{\text {Rdmax }}$ was calculated in accordance with PD 6687-1 (BSI, 2010), but was not critical for any of the tested beams. All the stirrups were assumed to yield on the basis of strain measurements. Ratios of the measured to calculated failure loads $\left(P_{\text {test }} / P_{\text {calc }}\right)$ are presented in Table 2 for each shear span, with the shear span in which failure occurred highlighted in bold. Table 2 shows that all the predictions are safe but the relative accuracy of each method depends on the loading arrangement and presence or otherwise of shear reinforcement.

\section{Strut-and-tie modelling}

Strut-and-tie modelling is a powerful technique for the design and analysis of D regions like beam-column joints (Vollum and Newman, 1999) and deep beams for which it is a practical alternative to NLFEA-based design procedures such as that of Amini Najafian et al. (2013). Both MC2010 and Eurocode 2 allow STM to be used for modelling shear enhancement near supports. Both codes give design concrete strengths for struts, with and without transverse tension, and nodes which are summarised in Table 4. Figure 4 shows the geometry of the proposed STM with and without shear reinforcement. Only essential details are given here as the development of the STM is described in detail elsewhere (Fang, 2014; Vollum and Fang, 2014). The stirrup forces in Figures 4(a) and 4(b) are subdivided into components $T_{\mathrm{s} 1}$ and $T_{\mathrm{s} 2}$ as shown and $C_{\mathrm{III}}, C_{\mathrm{IV}}$ and $C_{\mathrm{VI}}$ are the horizontal components of force resisted by struts III, IV and VI. The STM geometry depends on the magnitude of $P_{2}$ relative to $T_{\mathrm{s} 1}+T_{\mathrm{s} 2}$ as shown in Figure 4. STMa in Figure 4(a) ceases to be applicable when $T_{\mathrm{s} 1}+T_{\mathrm{s} 2}>P_{2}$ because the vertical component of force in strut VI is no longer sufficient to balance $T_{\mathrm{s} 1}+T_{\mathrm{s} 2}$. In this case, STMb of Figure 4(b) should be used. Figure 4(c) shows the geometry of the STM when stirrups are not present. Failure is assumed to occur in flexure, shear or bearing provided the flexural reinforcement is sufficiently anchored. Shear failure is assumed to occur due to combined yielding of the stirrups and crushing of strut III at its bottom end. As strut VII is fan shaped, it is assumed to be adequate provided that the bearing stress at the bottom node does not exceed the Eurocode 2 limit of $0.85 v f_{\text {cd }}$ for $C-C-T$ nodes, in which case bearing failure is critical. The bearing stress is not checked at the back of the bottom node as

\begin{tabular}{|c|c|c|c|c|}
\hline & $C-C-C$ node & $C-C-T$ node & Strut III $C-C-T$ node interface & $\begin{array}{l}\text { Strut III } C-C-C \text { node } \\
\text { interface }\end{array}$ \\
\hline STM-Eurocode 2 & $\left(1-\frac{f_{\mathrm{ck}}}{250}\right) \frac{f_{\mathrm{ck}}}{\gamma_{\mathrm{c}}}$ & $0.85\left(1-\frac{f_{c k}}{250}\right) \frac{f_{c k}}{\gamma_{c}}$ & $0.60\left(1-\frac{f_{c k}}{250}\right) \frac{f_{c k}}{\gamma_{c}}$ & $\left(1-\frac{f_{\mathrm{ck}}}{250}\right) \frac{f_{\mathrm{ck}}}{\gamma_{\mathrm{c}}}$ \\
\hline STM-MCFT'a & $0.85 \phi f_{\mathrm{ck}}$ & $0.85 \phi f_{c k}$ & $\phi f_{\mathrm{ck}} /\left(0.8+170 \varepsilon_{1}\right) \leqslant 0.85 \phi f_{\mathrm{ck}}^{\mathrm{b}}$ & $0.85 \phi f_{\mathrm{ck}}$ \\
\hline STM-MC2010 & $1 \cdot 0\left(\frac{30}{f_{c k}}\right)^{1 / 3} \frac{f_{c k}}{\gamma_{c}}$ & $0.75\left(\frac{30}{f_{c k}}\right)^{1 / 3} \frac{f_{c k}}{\gamma_{c}}$ & $0.55\left(\frac{30}{f_{c k}}\right)^{1 / 3} \frac{f_{c k}}{\gamma_{c}}$ & $1 \cdot 0\left(\frac{30}{f_{c k}}\right)^{1 / 3} \frac{f_{c k}}{\gamma_{c}}$ \\
\hline
\end{tabular}
this is not required by Eurocode 2.

\footnotetext{
${ }^{\mathrm{a}} \phi$ is a capacity reduction factor with a recommended design value of 0.65 .

b $\frac{\varepsilon_{1}}{=}=\left(\varepsilon_{\mathrm{L}}+0.002\right) \cot ^{2} \theta$, where $\theta$ is defined in Figure 4 and $\varepsilon_{\mathrm{L}}$ is the strain in the flexural reinforcement corresponding to $T=T_{i}^{\prime}+T_{\mathrm{d}}$.

c Applicable for strut angles $\theta<65^{\circ}$.
} 


\section{Derivation of design equations for STM}

The design equations are derived from considerations of geometry and equilibrium following the procedure adopted by Sagaseta and Vollum (2010) for beams with single concentrated loads within $2 d$ of supports. Only essential details are given here as the model is described in more detail elsewhere (Vollum and Fang, 2014). The design shear resistance is defined in terms of the stirrup force $T_{\mathrm{s} 1}$ as follows

19. $V_{\mathrm{Rd}}=P_{1}+P_{2}=P_{1}(1+\kappa)=\frac{T_{\mathrm{s} 1}}{(1-\lambda)}$

where $\lambda V_{\mathrm{Rd}}$ is the vertical component of force in strut III at failure, $\kappa=P_{2} / P_{1}$ and $T_{\mathrm{s} 1}$ is the yield capacity of the effective stirrups within $a_{\mathrm{v} 1}$.

Consideration of horizontal equilibrium at the bottom node leads to the following relationships

20. $T_{\mathrm{d}}=\beta T=\frac{\beta}{1-\beta} T_{i}^{\prime}=\frac{\beta}{1-\beta} T_{\mathrm{s} 1} \cot \alpha$

21. $T_{\mathrm{d}}=\lambda V_{\mathrm{Rd}} \cot \theta=\frac{\lambda}{1-\lambda} T_{\mathrm{s} 1} \cot \theta$

in which $T=T_{\mathrm{d}}+T_{i}^{\prime}$ is the force in the flexural reinforcement at the bottom node, $T_{\mathrm{d}}$ and $T_{i}^{\prime}$ are the horizontal components of force in struts III and VII, respectively, and $\alpha, \beta$ and $\theta$ are defined in Figure 4.

Equating Equations 20 and 21 and rearranging leads to the following equation for $\cot \alpha$

22. $\cot \alpha=\frac{\lambda}{\beta}\left(\frac{1-\beta}{1-\lambda}\right) \cot \theta$

The angles $\alpha$ and $\theta$ can be calculated from geometry in terms of $T_{\mathrm{s} 1}, T_{\mathrm{s} 2}, \beta, \lambda$ and the assumed flexural compressive stress $f_{\mathrm{cnt}}$ as follows

23. $\cot \alpha=\frac{e_{1}+0 \cdot 5 \lambda l_{\mathrm{b}}}{h-0 \cdot 5 T_{\mathrm{s} 1} \cot \alpha / b f_{\mathrm{cnt}}-c(1+\beta)}$

$$
\cot \theta=\frac{X}{Y}=
$$

24. $\frac{a_{1}+W-0 \cdot 5 l_{\mathrm{b}}(1-\lambda)}{h-\left\{T_{\mathrm{s} 1} \cot \alpha+\left[0 \cdot 5 \lambda T_{\mathrm{s} 1} /(1-\lambda)\right] \cot \theta\right\} / b f_{\mathrm{cnt}}-c \beta}$

in which the dimensions $e_{1}, X, Y$ and $W$ are defined in Figure 4. $W$ is the horizontal distance between $P_{1}$ and the intersection of the centreline of strut III with the line of action of $C_{\text {III. If }}$ $P_{2} \geqslant T_{\mathrm{s} 1}+T_{\mathrm{s} 2}$, consideration of geometry (see Figure 4(a)) and equilibrium leads to

$$
\begin{aligned}
& \left\{T_{\mathrm{s} 1}[\lambda-1 /(1+\kappa)]-T_{\mathrm{s} 2}(1-\lambda)\right\} \\
& {\left[a_{2}-a_{1}-\frac{0 \cdot 5 l_{\mathrm{t}}(1-\lambda)\left(T_{\mathrm{s} 1}+T_{\mathrm{s} 2}\right)(1+\kappa)}{k T_{\mathrm{s} 1}}\right]} \\
& W=\frac{+T_{\mathrm{s} 2}(1-\lambda)\left(e_{2}-a_{1}\right)}{\lambda T_{\mathrm{s} 1}}
\end{aligned}
$$

in which the dimensions $e_{1}$ and $e_{2}$ define the positions of the centrelines of the stirrup forces $T_{\mathrm{s} 1}$ and $T_{\mathrm{s} 2}$ as shown in Figure 4(a).

If $P_{2}<T_{\mathrm{s} 1}+T_{\mathrm{s} 2}$, consideration of Figure 4(b) leads to

26. $W=\frac{[\lambda(1+\kappa)-1]\left(e_{2}-a_{1}\right)}{\lambda(1+\kappa)}$

At failure, the horizontal component of force in strut III is given by

27. $T_{\mathrm{d}}=b f_{\mathrm{csb}}\left(\lambda l_{\mathrm{b}} \sin \theta+2 c \beta \cos \theta\right) \cos \theta$

where $f_{\text {csb }}$ is the concrete strength at the bottom end of strut III.

Equating Equations 20 and 27 for $T_{\mathrm{d}}$ and rearranging gives

28. $\beta=\frac{Y+Y \cot ^{2} \theta-\lambda l_{\mathrm{b}}}{2 c \cot \theta} \leqslant 1$

in which

29. $Y=\frac{\lambda}{(1-\lambda)} \frac{T_{\mathrm{s} 1}}{b f_{\mathrm{csb}}}$

In the case of beams without shear reinforcement (see Figure 4(c)), strut VII vanishes, $\lambda=\beta=1$ and 
30.

$$
\cot \theta=\frac{a_{1}+\kappa a_{2}}{(1+\kappa)\left(h-c-\frac{0 \cdot 5 T_{\mathrm{d}}}{b f_{\mathrm{cnt}}}\right)}
$$

where $T_{\mathrm{d}}$ is given by Equation 27

\section{Design concrete strengths}

The design strength at the bottom end of strut III was calculated in accordance with MC2010, Eurocode 2 and the modified compression field theory (MCFT) of Collins et al. (2008). The corresponding design concrete strengths are given in Table 4. The upper limit of $0.85 \phi f_{\mathrm{ck}}$ in the MCFT is applicable to the ends of struts not crossed by tension ties. The flexural compressive stress $f_{\text {cnt }}$ was taken as the relevant $C-C-C$ node strength from Table 4 . All the STM strength assessments were carried out with $\gamma_{\mathrm{c}}=\gamma_{\mathrm{s}}=\phi=1 \cdot 0$.

\section{Solution procedure for STM}

The STM geometry, and hence failure load, can be calculated once $\lambda, \cot \theta$ and $f_{\text {csb }}$ are known. The stress $f_{\text {csb }}$ is predefined in STM-Eurocode 2 and STM-MC2010, but depends on the flexural reinforcement strain and $\cot \theta$ in STM-MCFT. The unknowns $\lambda$ and $\cot \theta$ can be found from Equations $22-24$ and 28 using a nonlinear equation solver like the generalised reduced gradient (GRG2) non-linear solver in Microsoft Excel (Microsoft, 2014). The first step is to evaluate the right-hand sides of Equations 2224 and 28 in terms of assumed values for $\lambda_{\text {est }}, \cot \theta_{\text {est }}$ and $f_{\text {csb est }}$. The GRG2 solver can then be used to find the values of $\lambda_{\text {est }}$, $\cot \theta_{\text {est }}$ and $f_{\text {csb est }}$ at which the assumed and calculated (e.g. righthand sides of Equations 22-24 and 28) values converge.

\section{Non-linear finite-element analysis}

The response of the tested beams was simulated with NLFEA (Fang, 2014). Both two-dimensional (2D) and three-dimensional (3D) analyses were carried out with Diana (TNO, 2007) using its fixed crack total strain model. The concrete compressive behaviour was modelled with the parabolic stress-strain relationship of Feenstra (1993), which relates the compressive stress after failure to the compressive fracture energy $G_{\mathrm{c}}-$ taken as 100 times the tensile fracture energy $G_{\mathrm{f}}$. The maximum concrete compressive stress was related to the principal tensile strain in accordance with the recommendations of Vecchio and Collins (1993). The effect of confinement was modelled in the 3D NLFEA using the approach of Selby and Vecchio (1997). Tension softening was modelled with the Hordijk (1991) model, which relates the tensile stress after cracking to $G_{f}$, which was calculated using Model Code 1990 (CEB, 1993). Poisson's ratio was taken as zero, as proposed by Vecchio and Collins (1993) for the MCFT. The concrete tensile strength was taken as $0 \cdot 33 \sqrt{f_{\mathrm{ck}}}$ as adopted by Sagaseta and Vollum (2010). The shear retention factor was determined by sensitivity studies on the tested beams and was taken as 0.25 in the $2 \mathrm{D}$ analyses and 0.07 in the $3 \mathrm{D}$ analyses. The concrete elastic modulus was calculated in terms of the concrete compressive strength with Eurocode 2. The reinforce- ment was modelled with embedded elements in which reinforcement strains are calculated from the displacements of the concrete element assuming perfect bond (TNO, 2007). The reinforcement was conservatively assumed to be a von Mises perfectly elasto-plastic material with the yield strengths $f_{\mathrm{y}}$ shown in Table 3. Following a mesh sensitivity study (Fang, 2014), ten elements of equal depth were used through the beam depth in both the $2 \mathrm{D}$ and $3 \mathrm{D}$ analyses. The elements were approximately $50 \mathrm{~mm}$ square in elevation but their exact width was varied to give a whole number of equal width elements between the edges of the load and support plates. Three equal width elements were used through the beam thickness in the $3 \mathrm{D}$ analyses. It was found necessary to locally increase the concrete strength adjacent to the loading plates in the $2 \mathrm{D}$ analyses of beams without flexural compression reinforcement to prevent premature failure. The strength was locally increased by a multiple of three, above which further enhancement had no effect on the calculated failure load (Fang, 2014).

Table 5 gives values of $P_{\text {test }} / P_{\text {calc }}$ obtained using $2 \mathrm{D}$ and 3D NLFEA. Both analyses were reasonably accurate, with little advantage being gained from 3D NLFEA which was much more time consuming than 2D NLFEA. Figures 5 and 6 show typical comparisons between measured and predicted reinforcement strains. The agreement is reasonably good and shows that the NLFEA was able to simulate aspects of the observed structural response. For example, Figure 6 shows that the positions of the peak measured and predicted stirrup strains overlap. Fang (2014) also showed that the peak predicted strains occurred at or near the intersection of the stirrups with the critical shear crack as observed. The measured strains in Figure 6 show that all the stirrups yielded in beam S1-2, which was typical.

\section{Evaluation of STM and comparison with other methods}

Failure loads were calculated for all the tested beams using the STM. The failure loads of beams S1-2 and S2-2 with two point loads and stirrups were calculated assuming $T_{\mathrm{s} 1}=T_{\mathrm{s} 2}$ with $\kappa=P_{2} / P_{1}=1000$. The distance $a_{1}$ to $P_{1}$ was taken as $475 \mathrm{~mm}$, as in tests $\mathrm{S} 1-1$ and $\mathrm{S} 2-1$, but the resulting failure loads are insensitive to this assumption. All the stirrups were assumed to be effective. Both shear spans were analysed even though the shear span with the narrowest bearing plate is predicted to be critical in all cases. In fact, half of the 12 beams failed in the shear span supported by the widest bearing plate. This is significant since it suggests that the strategy of increasing shear strength by increasing bearing plate width could lead to unsafe designs. The results are given in Table 5, which shows that the STM-MCFT predictions are generally better than those of STM-Eurocode 2 and STM-MC2010, which are almost identical. The STM-Eurocode 2 and STM-MC2010 predictions are unsafe for all the beams without shear reinforcement except the B2 beams with $a_{\mathrm{v} 1} / d \sim 0.7$ and beam A-1. Table 5 also gives the strength predictions obtained with $2 \mathrm{D}$ and $3 \mathrm{D}$ NLFEA. The STM-MCFT predictions are seen to compare favourably with 


\begin{tabular}{|c|c|c|c|c|c|c|c|c|c|}
\hline \multirow[t]{3}{*}{ Beam } & \multirow[t]{3}{*}{$P_{\text {test }}: \mathrm{kN}$} & \multicolumn{8}{|c|}{$P_{\text {test }} / P_{\text {calc }}$} \\
\hline & & \multicolumn{2}{|c|}{ STM-Eurocode 2} & \multicolumn{2}{|c|}{ STM-MCFT } & \multicolumn{2}{|c|}{ STM-MC2010 } & \multicolumn{2}{|c|}{ NLFEA } \\
\hline & & $\mathrm{L}^{\mathrm{a}}$ & $\mathrm{R}^{\mathrm{a}}$ & $\mathrm{L}^{\mathrm{a}}$ & $\mathrm{R}^{\mathrm{a}}$ & $\mathrm{L}^{\mathrm{a}}$ & $\mathrm{R}^{\mathrm{a}}$ & $2 D$ & $3 D$ \\
\hline B1-25 & 368 & 0.74 & 0.82 & $1 \cdot 16$ & $1 \cdot 22$ & 0.75 & 0.84 & 0.99 & 1.04 \\
\hline B1-50 & 352 & 0.61 & 0.65 & 1.06 & 1.08 & 0.62 & 0.66 & 0.98 & 1.06 \\
\hline B2-25 & 977 & 1.09 & $1 \cdot 25$ & $1 \cdot 15$ & $1 \cdot 20$ & $1 \cdot 11$ & $1 \cdot 28$ & 1.04 & $1 \cdot 28$ \\
\hline B2-50 & 929 & 0.92 & 1.02 & 1.07 & 1.09 & 0.94 & 1.04 & 1.05 & $1 \cdot 20$ \\
\hline$A-2$ & 349 & 0.72 & 0.89 & 1.06 & $1 \cdot 26$ & 0.70 & 0.87 & 0.94 & 1.01 \\
\hline S1-2 & 601 & 0.89 & 1.04 & 1.03 & $1 \cdot 14$ & 0.86 & 1.03 & 0.96 & 1.02 \\
\hline S2-2 & 820 & 1.07 & $1 \cdot 23$ & $1 \cdot 17$ & $1 \cdot 28$ & $1 \cdot 04$ & $1 \cdot 22$ & $1 \cdot 25$ & $1 \cdot 18$ \\
\hline B3-25 & 480 & 0.73 & 0.83 & 0.95 & 1.00 & 0.75 & 0.84 & 0.79 & 1.00 \\
\hline B3-50 & 580 & 0.78 & 0.84 & $1 \cdot 12$ & $1 \cdot 13$ & 0.79 & 0.85 & 1.06 & 0.99 \\
\hline$A-1$ & 823 & $1 \cdot 37$ & $1 \cdot 76$ & 1.63 & 1.98 & $1 \cdot 32$ & $1 \cdot 71$ & $1 \cdot 28$ & 1.33 \\
\hline S1-1 & 1000 & $1 \cdot 22$ & $1 \cdot 55$ & $1 \cdot 22$ & $1 \cdot 44$ & $1 \cdot 20$ & $1 \cdot 52$ & $1 \cdot 32$ & $1 \cdot 39$ \\
\hline S2-1 & 1179 & $1 \cdot 31$ & $1 \cdot 64$ & $1 \cdot 27$ & $1 \cdot 47$ & $1 \cdot 29$ & $1 \cdot 62$ & 1.43 & $1 \cdot 35$ \\
\hline
\end{tabular}

${ }^{a}$ Calculated for right (R)/left (L) shear span as defined in Figure 3 (bold type denotes critical shear span in test)

Table 5. Measured and predicted STM failure loads

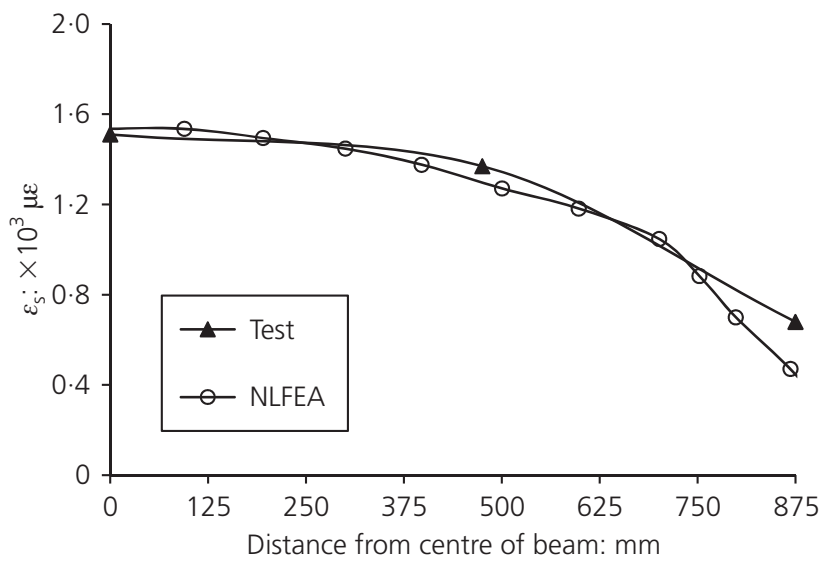

Figure 5. Comparison between predicted and experimental tensile strains along the flexural reinforcement in beam S1-1 at $645 \mathrm{kN}$ the NLFEA predictions, which depend significantly on userdefined input parameters of which the shear retention factor has the greatest effect. Table 6 presents a statistical analysis of the accuracy of the calculated strengths of the tested beams for STM, NLFEA and codified sectional methods. BS 8110 and MC2010 give more consistent values of $P_{\text {test }} / P_{\text {calc }}$ than Eurocode 2 for beams with shear reinforcement. This is partly because both methods, unlike Eurocode 2, predict greater strengths for the beams with four point loads than the corresponding beams with two point loads.

\section{Parametric studies}

A series of parametric studies was carried out on beams with four point loads to investigate the influence of varying the loading ratio $\kappa=P_{2} / P_{1}$ on shear strength. The aim of the study was to investigate loading arrangements not considered in the tests. The

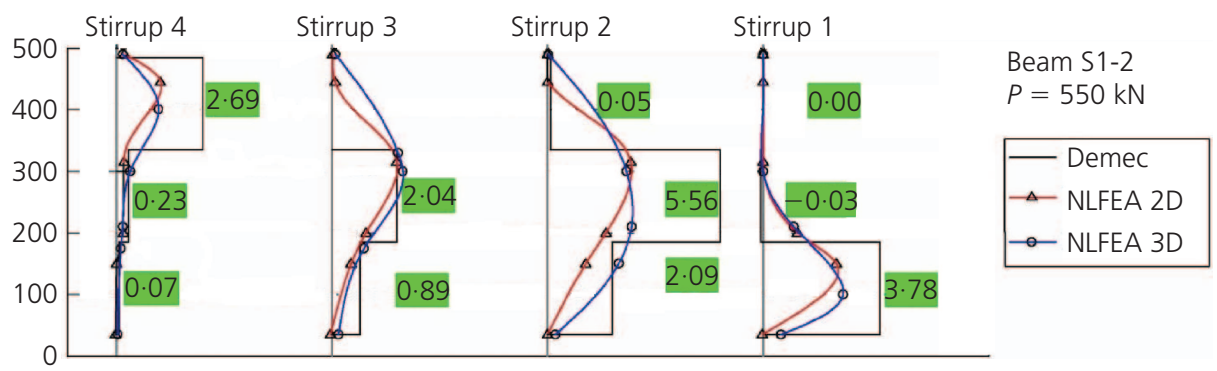

Figure 6. Comparison between measured and predicted stirrup strains in right-hand shear span of beam S1-2 at $P=550 \mathrm{kN}$ $\left(P_{\mathrm{u}}=601 \mathrm{kN}\right)$ (note: shaded numbers denote Demec strains $\left.\times 10^{3}\right)$ 


\begin{tabular}{|c|c|c|c|c|c|c|c|c|c|}
\hline \multicolumn{2}{|l|}{ Method } & \multicolumn{3}{|c|}{ Sectional } & \multicolumn{3}{|c|}{ STM- } & \multicolumn{2}{|c|}{ NLFEA } \\
\hline Beams & Statistic & Eurocode 2 & BS 8110 & MC2010 & Eurocode 2 & MCFT & MC2010 & $2 \mathrm{D}$ & $3 D$ \\
\hline \multirow[t]{2}{*}{ All } & Mean & 1.76 & $1 \cdot 57$ & 2.07 & $1 \cdot 13$ & $1 \cdot 27$ & $1 \cdot 12$ & 1.09 & $1 \cdot 16$ \\
\hline & COV & 0.28 & 0.19 & 0.43 & 0.32 & $0 \cdot 21$ & 0.31 & 0.17 & $0 \cdot 13$ \\
\hline \multirow[t]{2}{*}{ With stirrups } & Mean & $1 \cdot 43$ & $1 \cdot 39$ & $1 \cdot 26$ & $1 \cdot 36$ & $1 \cdot 33$ & $1 \cdot 35$ & $1 \cdot 24$ & $1 \cdot 23$ \\
\hline & COV & 0.28 & 0.07 & $0 \cdot 18$ & 0.21 & $0 \cdot 12$ & $0 \cdot 20$ & $0 \cdot 16$ & $0 \cdot 14$ \\
\hline
\end{tabular}

Table 6. Statistical analysis of $V_{\text {test }} / V_{\text {calc }}$ for tested beams

analyses were carried out on beams with the same geometry, reinforcement and loading positions as beams B3-25 with $f_{\text {ck }}=45.7 \mathrm{MPa}$ (see Figure 1), S1-1 with $f_{\text {ck }}=36 \mathrm{MPa}$ (see Figure 2(b)) and S2-1 with $f_{\text {ck }}=36 \mathrm{MPa}$ (see Figure 2(c)). The loading positions are given in Table 1 , which should be read in conjunction with Figure 3.

Failure loads were initially obtained with 2D and 3D NLFEA using the same finite-element meshes, material parameters and solution procedure as used for the tested beams. The resulting shear strengths are compared with those given by STM in Figure 7 , along with relevant test data from this programme. Figure 7 shows that of the STM, STM1-MCFT gives the best estimates of the measured beam strengths as well as simulating the observed increase in strength with $P_{1} / P_{2}$ most accurately. The NLFEA predictions are comparable but less consistent than the STM-MCFT predictions which seem better. The 3D NLFEA is slightly more conservative than the 2D NLFEA, which overestimates the strength of beam B3-25. More conservative 2D NLFEA strength predictions could be achieved by reducing the shear retention factor $\beta$ from its adopted value of 0.25 but this was not done as $\beta$ was chosen to give a reasonable fit to all the test results.

Figure 8 compares the code predictions with STM-MCFT, which is the best of the STMs, and relevant test data. The BS 8110 predictions are seen to be closest to the STM-MCFT predictions. The BS 8110 predictions become independent of $P_{2} / P_{1}$ above a threshold value of $P_{2} / P_{1}$ because failure plane $P_{1}$ in Figure 3(c) becomes critical. Failure loads were also calculated with Equation 4 using $V_{\text {Rdav1 }}$ and $V_{\text {Rdav2 }}$ from Equations 5(a) and 5(b) of BS 8110. Figure 8 shows that the resulting predictions (BS 8110 Equation 4) are acceptable but more conservative than given by BS 8110. The MC2010 shear enhancement method works reasonably well for the beams with shear reinforcement (level 3) but is overly conservative for beams without shear reinforcement (level 2). Three Eurocode 2 predictions are given for beams with shear reinforcement which are denoted Eurocode 2 Equation 1, Eurocode 2 Equation 2 and Eurocode 2 Equation 4 in Figure 8. The predictions correspond to the shear enhancement methods of equations 1 and 2 of $\mathrm{MC} 2010$ with $V_{\mathrm{Rd}}=\max \left(V_{\mathrm{Rd}, \mathrm{c}}\right.$ from Equation $6, V_{\mathrm{Rd}, \mathrm{s}}$ from Equation 7) and Equation 4 with $V_{\mathrm{Rdav}}$

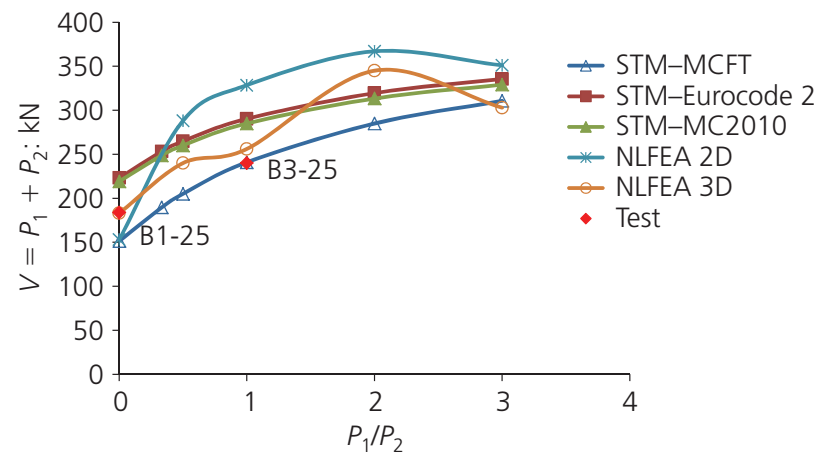

(a)

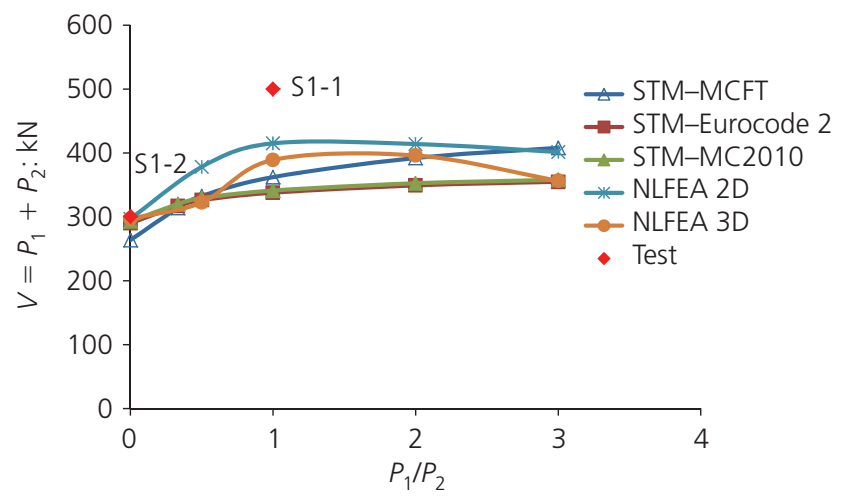

(b)

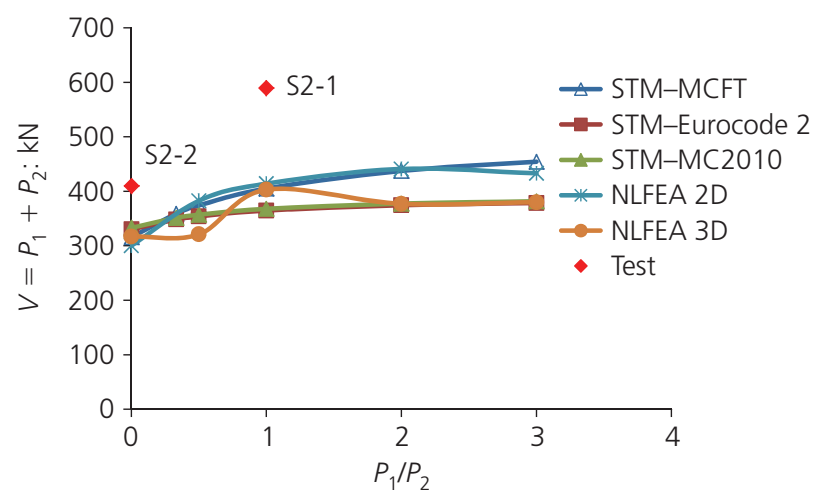

(c)

Figure 7. Influence of load ratio $P_{1} / P_{2}$ on shear strengths calculated with STM for: (a) beam B3-25; (b) beam S1-1; (c) beam S1-2 


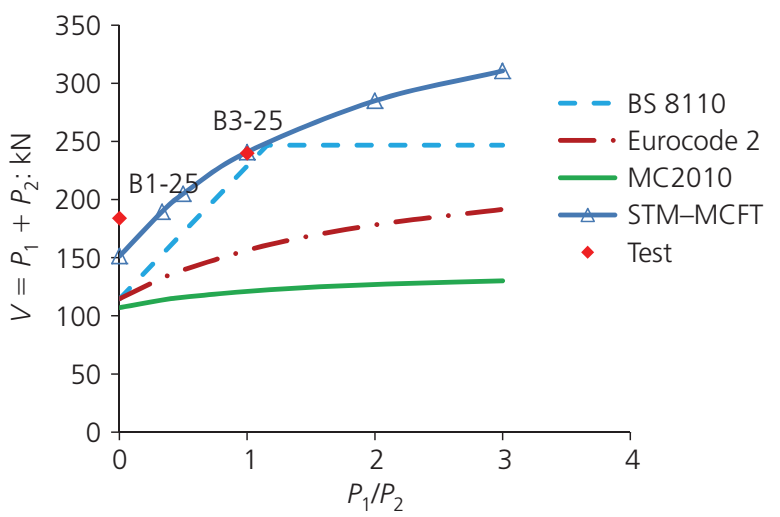

(a)

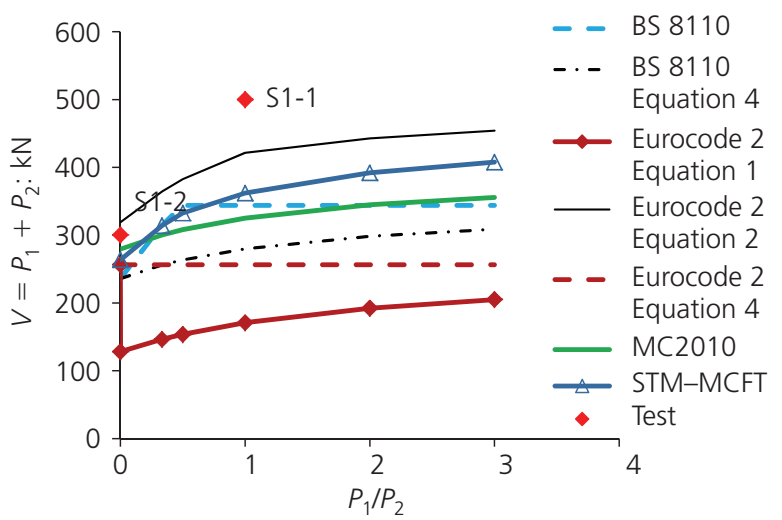

(b)

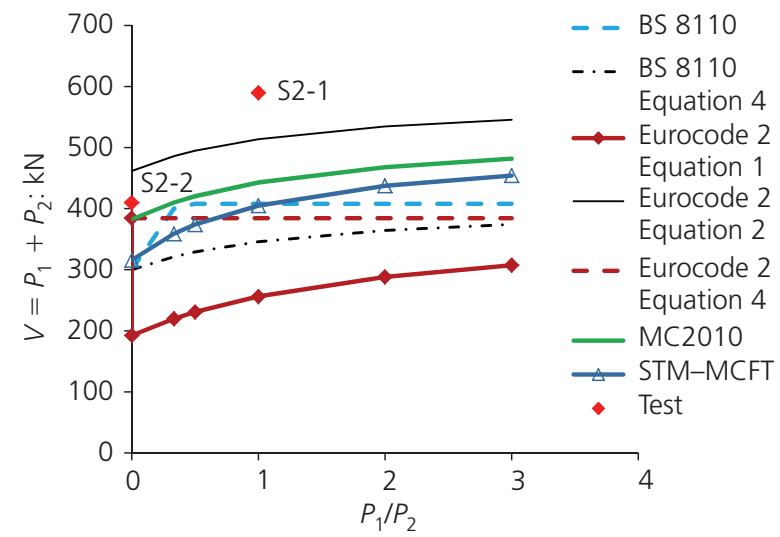

(c)

Figure 8. Influence of load ratio $P_{1} / P_{2}$ on shear strengths calculated with STM-MCFT and code based methods for: (a) beam B3-25; (b) beam S1-1; (c) beam S1-2

and $V_{\text {Rdav2 }}$ from Equations 1(a) and 1(b), respectively. The spike in the Eurocode 2 Equation 1 results of Figures 8(b) and 8(c) arises because Equation (1a) governs if $P_{1} / P_{2}>0$ but Equation (1b) if $P_{1} / P_{2}=0$. Eurocode 2 Equation 2 gives better predictions than Eurocode 2 Equation 1, but they are relatively high compared with the MC2010 and STM1-MCFT predictions. Eurocode 2 Equation 4 predicts shear resistance to be independent of $P_{1} / P_{2}$ since $\beta_{1} / n_{\mathrm{av} 1}=\beta_{2} / n_{\mathrm{av} 2}$ for beams S1-1 and S1-2.

\section{Comparison with other test results}

The analyses in this paper show that the Eurocode 2 method of shear enhancement requires improvement for beams with shear reinforcement. There is a lack of data to properly assess these methods for beams with multiple point loads within $2 d$ of supports. Therefore, potential improvements to the Eurocode 2 method of shear enhancement were assessed with data from 57 beams (Lehwalter (1988) (one beam); Regan (1971) (six beams); Tan et al. (1995) (one beam); Tan et al. (1997) (two beams); Vollum and Tay (2001) (two beams); Clark (1951) (27 beams); Kong and Rangan (1998) (two beams); Sagaseta and Vollum (2010) (six beams); Birrcher et al. (2013) (eight beams) and the authors' beams S1-2 and S2-2) with $a_{\mathrm{v}} / d$ between 1 and 2, shear reinforcement and single point loads within $2 d$ of the supports. All the beams had just vertical stirrups except those of Birrcher et al. (2013), which also had horizontal web reinforcement. Further details of all these beams except those of Birrcher et al. (2013) and this programme can be found in Table 3 of Sagaseta and Vollum (2010). The enhanced shear strengths $V_{\text {calc }}$ of these beams were calculated using the following five methods, with $V_{\mathrm{Rd}, \mathrm{c}}$ from Eurocode 2, as well as STM-MCFT and MC2010.

BS 8110:

$$
V_{\text {calc }}=\left(V_{\mathrm{Rd}, \mathrm{c}}+0 \cdot 5 n_{\mathrm{av}} A_{\mathrm{sw}} f_{\mathrm{yd}}\right) / \beta
$$

Eurocode 2 Equation 1(b):

$$
V_{\text {calc }}=\max \left(V_{\mathrm{Rd}, \mathrm{c}}, n_{\mathrm{av}} A_{\mathrm{sw}} f_{\mathrm{yd}}\right) / \beta
$$

Eurocode 2 Equation 2:

$$
V_{\text {calc }}=\max \left(V_{\mathrm{Rd}, \mathrm{c}}, V_{\mathrm{Rd}, \mathrm{s}} \text { from Equation } 7\right) / \beta
$$

Eurocode 2 M1:

$$
V_{\mathrm{calc}}=\left(V_{\mathrm{Rd}, \mathrm{c}}+n_{\mathrm{av}} A_{\mathrm{sw}} f_{\mathrm{yd}}\right) / \beta
$$

Eurocode $2 \mathrm{M} 2$ :

$$
V_{\text {calc }}=\max \left(V_{\mathrm{Rd}, \mathrm{c}} / \beta, \quad V_{\mathrm{Rd}, \mathrm{s}} \text { from Equation } 7\right)
$$

The STM failure loads were calculated with $T_{\mathrm{s} 1}=T_{\mathrm{s} 2}, \quad P_{1}$ positioned at the centre of the clear shear span and $\kappa=P_{2} / P_{1}=1000$. The resulting failure loads are similar to those given by the STM of Sagaseta and Vollum (2010) for beams with one point load within $2 d$ of supports. Eurocode 2 Equation 2 uses equation 2 of MC2010 but $V_{\mathrm{Rd}}$ is calculated with Eurocode 2. Eurocode $2 \mathrm{M} 1$ is given in the Eurocode 2 commentary (European Concrete Platform ASBL, 2008) but was 


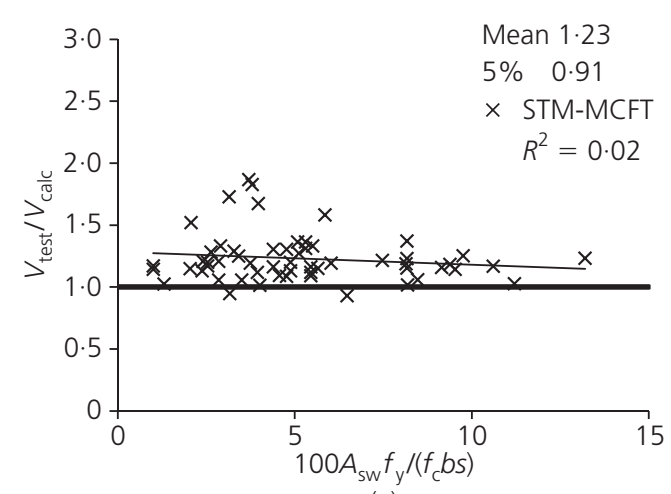

(a)

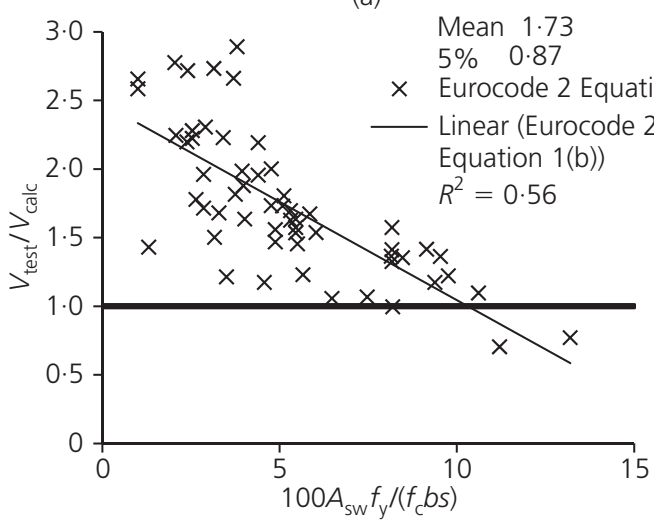

(c)

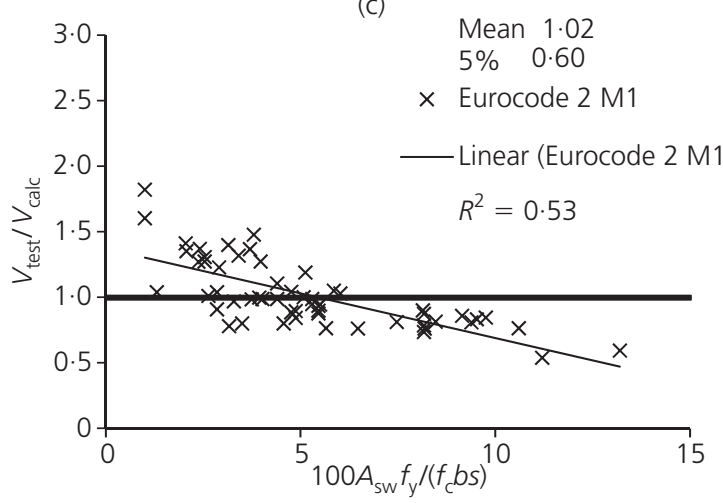

(e)

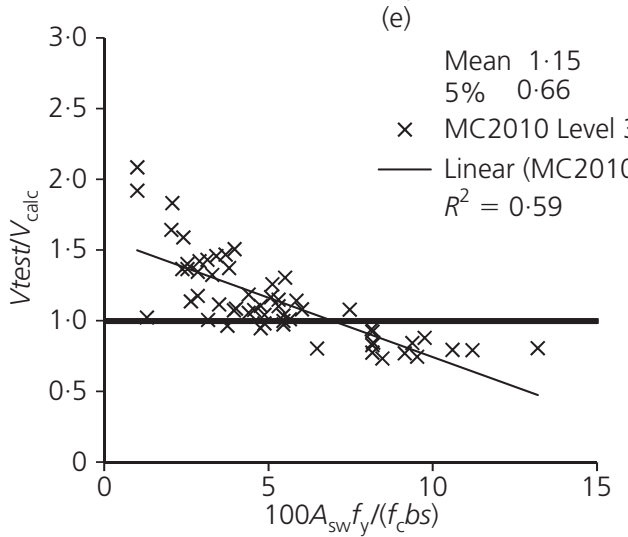

(g)

Figure 9. Comparison between measured and calculated shear strengths for: (a) STM-MCFT; (b) BS8110; (c) Eurocode 2 Equation 1(b); (d) Eurocode 2 Equation 2; (e) Eurocode $2 \mathrm{M1}$; (f) Eurocode 2 M2; (g) MC2010 level 3

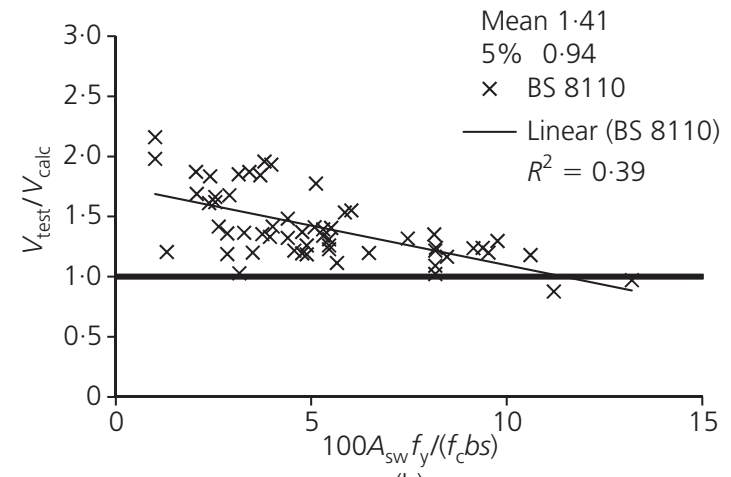

(b)
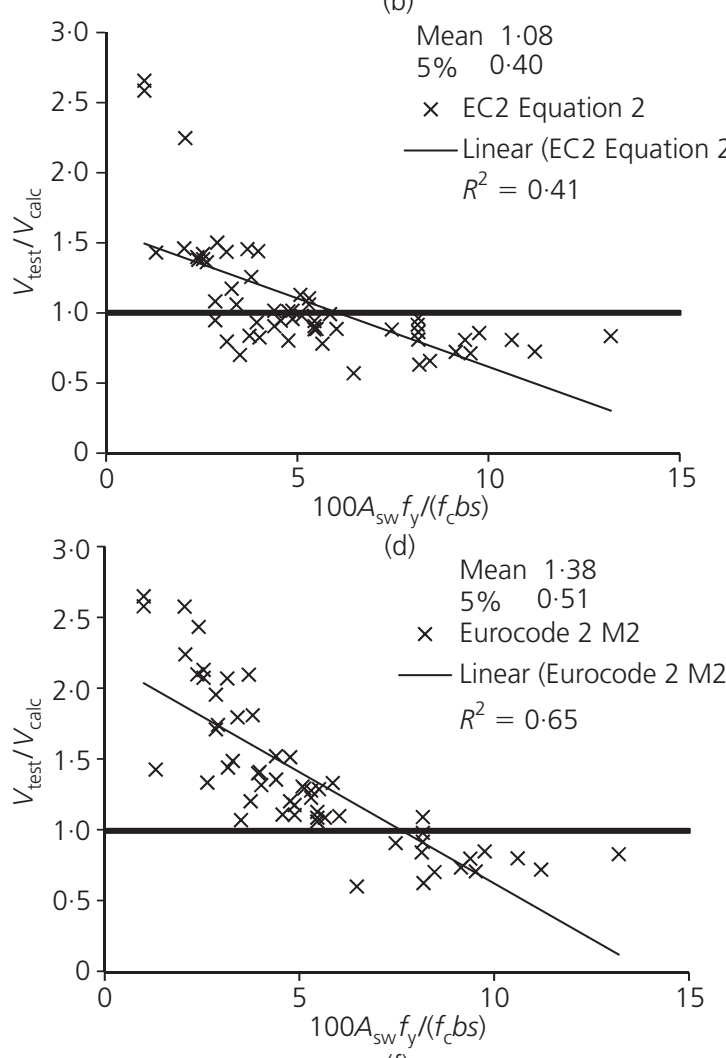

(f) 
omitted from the final version of the code. Like Equations 1 and 5 of Eurocode 2 and BS 8110, respectively, Eurocode 2 M2 applies no enhancement to the shear resistance provided by the shear reinforcement, which is calculated using the standard Eurocode 2 method for beams. $V_{\text {test }} / V_{\text {calc }}$ is plotted against the shear reinforcement ratio $100 A_{\mathrm{sw}} f_{\mathrm{y}} /\left(b s f_{\mathrm{c}}\right)$ for each design method in Figure 9, which also shows the trend between the two. The correlation between $V_{\text {test }} / V_{\text {calc }}$ and $100 A_{\text {sw }} f_{\mathrm{y}} /\left(b s f_{\mathrm{c}}\right)$ is reflected in the $R^{2}$ value, which is 1 for perfect correlation. The figures also show that, as well as being most accurate, the STM-MCFT predictions are the only ones that are independent of $100 A_{\mathrm{sw}} f_{\mathrm{y}} / b s f_{\mathrm{c}}$. BS 8110 performs best of the sectional methods and significantly better than the current Eurocode 2 method (Equation 1(b)), which is overly conservative at low reinforcement ratios. Eurocode 2 Equation 2, Eurocode 2 M1, Eurocode 2 M2 and MC2010 all overestimate shear resistance at high shear reinforcement ratios. This is even the case for Eurocode 2 M2 in which no enhancement is applied if the shear resistance is governed by shear reinforcement. With the exception of Eurocode $2 \mathrm{M} 1$, the overestimate arises in part because these methods fail to acknowledge that shear reinforcement is only effective if placed within the central three-quarters of the clear shear span $a_{\mathrm{v}}$. The overestimate is also consistent with the previous finding of Sagaseta and Vollum (2011b) that Eurocode 2 overestimates the shear strength of beams with rectangular cross-sections and high shear reinforcement ratios. Table 7 presents a statistical analysis which confirms that the STM-MCFT and BS 8110 methods are most accurate.

\section{Conclusions}

Twelve beams were tested to investigate the effects of loading arrangement and shear reinforcement ratio on the relative accuracies of the shear enhancement methods in MC2010, BS 8110 and Eurocode 2. Different support widths were adopted at each end of the beams to determine whether failure occurred on the side of the narrower support as predicted by STM. Notably, half the beams failed on the side of the wider support, which casts doubt on the realism of the underlying assumptions of STM and the strategy of increasing shear resistance by increasing support width. The Eurocode 2 method of shear enhancement is adequate for beams without shear reinforcement but not for beams with shear reinforcement, where it fails to predict the influence of loading arrangement. A STM is presented which is shown to give reasonable predictions of shear resistance of the tested beams, with the best predictions being obtained if the direct strut strength is calculated in accordance with the recommendations of the MCFT. The STM-MCFT and NLFEA predictions are shown to be of comparable accuracy but the STM has the advantage of not requiring calibration of input parameters. The BS 8110 method of modelling shear enhancement was found to be significantly better for beams with shear reinforcement than the methods of Eurocode 2 and MC2010, with the advantages particularly evident for beams with multiple point loads. Consequently, it is suggested that Equation 5 of BS 8110 is used to calculate the shear resistance $V_{\text {Rdav }}$ in future revisions of Eurocode 2. Multiple point loads are most easily handled using the BS 8110 approach of enhancing shear resistance. However, Equation 4 also gives reasonable results as shown in Figure 8.

\section{Acknowledgements}

The authors would like to acknowledge the financial support of The Concrete Centre, UK and the technical assistance of the staff of the Structures Laboratory at Imperial College London.

\section{REFERENCES}

Amini Najafian H, Vollum RL and Fang L (2013) Comparative assessment of finite element and strut and tie based design methods for deep beams. Magazine of Concrete Research 65(16): 970-986, http://dx.doi.org/10.1680/macr.13.00006.

Birrcher DB, Tuchscherer RG, Huizinga M and Bayrak O (2013) Minimum web reinforcement in deep beams. ACI Structural Journal 110(2): 297-306.

Brown MD and Bayrak O (2007) Investigation of deep beams with various load, configurations. ACI Structural Journal 104(6): 11-20.

BSI (1997) BS 8110. Part 1: Structural use of concrete: code of practice for design and construction. BSI, London, UK.

BSI (2004) European Standard EN-1992-1-1: 2004. Eurocode 2:

\begin{tabular}{lcccccccc}
\hline Method & STM MCFT & BS 8110 & $\begin{array}{c}\text { Eurocode 2 } \\
\text { Equation 1(b) }\end{array}$ & $\begin{array}{c}\text { Eurocode 2 } \\
\text { Equation 2 }\end{array}$ & $\begin{array}{c}\text { Eurocode 2 } \\
\text { M1 }\end{array}$ & $\begin{array}{c}\text { Eurocode 2 } \\
\text { M2 }\end{array}$ & $\begin{array}{c}\text { MC2010 } \\
\text { level 2 }\end{array}$ & $\begin{array}{c}\text { MC2010 } \\
\text { level 3 }\end{array}$ \\
\hline Mean & 1.23 & 1.41 & 1.73 & 1.08 & 1.02 & 1.38 & 1.34 & 1.15 \\
COV & 0.16 & 0.20 & 0.30 & 0.39 & 0.25 & 0.39 & 0.38 & 0.26 \\
Characteristic $^{b}$ & 0.91 & 0.94 & 0.87 & 0.40 & 0.60 & 0.51 & 0.51 & 0.66 \\
\hline
\end{tabular}

a Short-span beams used were 47 beams from Table 3 of Sagaseta and Vollum (2010), beams S1-2 and S2-2 from this program and eight beams from Birrcher et al. (2013).

b $5 \%$ lower characteristic strength. 
Design of concrete structures. Part 1, general rules and rules for buildings. BSI, London, UK.

BSI (2010) PD 6687-1. Background paper to the National Annexes to BS EN 1992-1 and BS EN 1992-3. BSI, London, UK.

CEB (1993) CEB-FIP Model Code 1990. Thomas Telford, London, UK.

Clark AP (1951) Diagonal tension in reinforced concrete beams. Journal of the American Concrete Institute 23(2): 145-156.

Collins MP, Bentz EC, Sherwood EG and Xie L (2008) An adequate theory for the shear strength of reinforced concrete structures. Magazine of Concrete Research 60(9): 635-650, http://dx.doi.org/10.1680/macr.2008.60.9.635.

European Concrete Platform ASBL (2008) Commentary Eurocode 2. European Concrete Platform, Brussels, Belgium.

Fang L (2014) Shear Enhancement in Reinforced Concrete Beams. PhD thesis, Imperial College London, London, UK.

Feenstra PH (1993) Computational Aspects of Biaxial Stress in Plain and Reinforced Concrete. PhD, Delft University of Technology, Delft, the Netherlands.

fib (Fédération Internationale du Béton) (2013) fib Model Code for Concrete Structures 2010. Ernst \& Sohn, Germany.

Hordijk DA (1991) Local Approach to Fatigue of Concrete. PhD thesis, Delft University of Technology, Delft, the Netherlands.

Jackson P, Salim S, Shave J and Denton S (2007) Shear enhancement at short shear spans in EN 1992. The Structural Engineer 85(23/24): 37-42.

Kong YL and Rangan BV (1998) Shear strength of highperformance concrete beams. ACI Structural Journal 94(6): 677-688.

Lehwalter N (1988) The Bearing Capacity of Concrete Compression Struts in Strut and Tie Models with Examples of Deep Beams. PhD thesis, Technical University of Darmstadt, Germany.

Microsoft (2014) Article 82890. See http:// support.microsoft.com/kb/82890 (accessed 29/06/2014).

Regan PE (1971) Shear in Reinforced Concrete - An Experimental Study. Construction Industry and Information Association (Ciria), London, UK.
Sagaseta J and Vollum RL (2010) Shear design of short-span beams. Magazine of Concrete Research 62(4): 267-282, http://dx.doi.org/10.1680/macr.2010.62.4.267.

Sagaseta J and Vollum RL (2011a) Influence of aggregate fracture on shear transfer through cracks in reinforced concrete. Magazine of Concrete Research 63(2): 119-137, http:// dx.doi.org/10.1680/macr.9.00191.

Sagaseta J and Vollum RL (2011b) Influence of beam crosssection, loading arrangement and aggregate type on shear strength. Magazine of Concrete Research 63(2): 139-155, http://dx.doi.org/10.1680/macr.9.00192.

Selby R and Vecchio F (1997) A constitutive model for analysis of reinforced concrete solids. Canadian Journal of Civil Engineering 24(3): 460-470.

Tan KH, Kong FK, Teng S and Guan S (1995) High-strength concrete deep beams with effective span and shear span variations. ACI Structural Journal 92(4): 395405.

Tan KH, Kong FK, Teng S and Weng LW (1997) Effect of web reinforcement on high-strength concrete deep beams. $A C I$ Structural Journal 94(5): 572-582.

TNO (2007) Finite Element Analysis Users Manual Release 9.2. TNO Diana, Delft, the Netherlands.

Vecchio FJ and Collins MP (1993) Compression response of cracked reinforced concrete. Journal of Structural Engineering ASCE 119(12): 3590-610.

Vollum RL and Fang L (2014) Shear enhancement in RC beams with multiple point loads. Engineering Structures 80: 389405.

Vollum RL and Newman JB (1999) Towards the design of eccentric beam-column joints. Magazine of Concrete Research 51(6): 397-407, http://dx.doi.org/10.1680/ macr.1999.51.6.397.

Vollum RL and Tay UL (2001) Strut and tie modelling of shear failure in short-span beams. Proceedings of the Concrete Communication Conference, UMIST, Manchester. British Cement Association and the Concrete Society, Camberley, Surrey, UK, pp. 193-199.

\section{WHAT DO YOU THINK?}

To discuss this paper, please submit up to 500 words to the editor at journals@ice.org.uk. Your contribution will be forwarded to the author(s) for a reply and, if considered appropriate by the editorial panel, will be published as a discussion in a future issue of the journal. 